\title{
The Evolution of the Goddard Profiling Algorithm (GPROF) for Rainfall Estimation from Passive Microwave Sensors
}

\author{
Christian Kummerow, ${ }^{*}$ Y. Hong, ${ }^{+}$W. S. Olson, ${ }^{\#}$ S. Yang, ${ }^{\#}$ R. F. Adler, ${ }^{@}$ J. McCollum, \& \\ R. Ferraro, \& G. Petty, ** D.-B. Shin, * and T. T. Wilheit ${ }^{+}+$ \\ *Department of Atmospheric Science, Colorado State University, Fort Collins, Colorado \\ +The Aerospace Corporation, Los Angeles, California \\ \#Joint Center for Earth Systems Technology, University of Maryland, Baltimore County, Baltimore, Maryland \\ ${ }^{\circledR}$ NASA Goddard Space Flight Center, Greenbelt, Maryland \\ ${ }^{\star}$ NOAA/NESDIS, Camp Springs, Maryland \\ **University of Wisconsin-Madison, Madison, Wisconsin \\ ${ }^{++}$Texas A\&M University, College Station, Texas
}

(Manuscript received 28 November 2000, in final form 5 June 2001)

\begin{abstract}
This paper describes the latest improvements applied to the Goddard profiling algorithm (GPROF), particularly as they apply to the Tropical Rainfall Measuring Mission (TRMM). Most of these improvements, however, are conceptual in nature and apply equally to other passive microwave sensors. The improvements were motivated by a notable overestimation of precipitation in the intertropical convergence zone. This problem was traced back to the algorithm's poor separation between convective and stratiform precipitation coupled with a poor separation between stratiform and transition regions in the a priori cloud model database. In addition to now using an improved convective-stratiform classification scheme, the new algorithm also makes use of emission and scattering indices instead of individual brightness temperatures. Brightness temperature indices have the advantage of being monotonic functions of rainfall. This, in turn, has allowed the algorithm to better define the uncertainties needed by the scheme's Bayesian inversion approach. Last, the algorithm over land has been modified primarily to better account for ambiguous classification where the scattering signature of precipitation could be confused with surface signals. All these changes have been implemented for both the TRMM Microwave Imager (TMI) and the Special Sensor Microwave Imager (SSM/I). Results from both sensors are very similar at the storm scale and for global averages. Surface rainfall products from the algorithm's operational version have been compared with conventional rainfall data over both land and oceans. Over oceans, GPROF results compare well with atoll gauge data. GPROF is biased negatively by $9 \%$ with a correlation of 0.86 for monthly $2.5^{\circ}$ averages over the atolls. If only grid boxes with two or more atolls are used, the correlation increases to 0.91 but GPROF becomes positively biased by $6 \%$. Comparisons with TRMM ground validation products from Kwajalein reveal that GPROF is negatively biased by $32 \%$, with a correlation of 0.95 when coincident images of the TMI and Kwajalein radar are used. The absolute magnitude of rainfall measured from the Kwajalein radar, however, remains uncertain, and GPROF overestimates the rainfall by approximately $18 \%$ when compared with estimates done by a different research group. Over land, GPROF shows a positive bias of $17 \%$ and a correlation of 0.80 over monthly $5^{\circ}$ grids when compared with the Global Precipitation Climatology Center (GPCC) gauge network. When compared with the precipitation radar (PR) over land, GPROF also retrieves higher rainfall amounts (20\%). No vertical hydrometeor profile information is available over land. The correlation with the TRMM precipitation radar is 0.92 over monthly $5^{\circ}$ grids, but GPROF is positively biased by $24 \%$ relative to the radar over oceans. Differences between TMI- and PR-derived vertical hydrometeor profiles below $2 \mathrm{~km}$ are consistent with this bias but become more significant with altitude. Above $8 \mathrm{~km}$, the sensors disagree significantly, but the information content is low from both TMI and PR. The consistent bias between these two sensors without clear guidance from the ground-based data reinforces the need for better understanding of the physical assumptions going into these retrievals.
\end{abstract}

\section{Introduction}

Microwave remote sensing of clouds and precipitation has been successfully used for a number of years

Corresponding author address: Dr. Christian D. Kummerow, Department of Atmospheric Science, Colorado State University, Fort Collins, CO 80523.

E-mail: kummerow@atmos.colostate.edu and continues to improve as new sensors become available. The Tropical Rainfall Measuring Mission (TRMM) carries the TRMM Microwave Imager (TMI), which is similar to the existing Special Sensor Microwave Imager (SSM/I) sensor but has an additional 10-GHz channel and significantly better spatial resolution. The instrument characteristics are described in Kummerow et al. (1998). TRMM employs two distinct algorithms to ob- 
tain rainfall from the TMI instrument. The first algorithm is designed to provide instantaneous rainfall rates, the vertical structure of precipitation and the associated latent heating. The algorithm, described here, is known as the Goddard profiling algorithm (GPROF) even though it now extends to researchers well beyond Goddard Space Flight Center. It was first described in the literature by Kummerow et al. (1996) but has undergone significant improvements in the last five years.

The second algorithm, for reference, is based upon the emission signatures of the 19.3- and 21.3-GHz channels to retrieve rainfall over radiometrically cold oceans. It is a very robust emission-based algorithm that minimizes retrieval assumptions but in the process is restricted to monthly mean oceanic rainfall accumulations over $5^{\circ}$-lat $\times 5^{\circ}$-long boxes instead of pixel-level retrievals. It has been used in the Global Precipitation Climatology Project (GPCP) estimate (Huffman et al. 1997) as well as TRMM. The algorithm is based on the technique developed by Change et al. (1993) and Wilheit et al. (1991). Chang et al. (1999) compared results of the technique from TMI and SSM/I data for six months of 1998 and found no significant differences between the two products.

In contrast to the emission algorithm described above, GPROF aims to retrieve the instantaneous rainfall and the rainfall vertical structure. This is made possible by the response functions for different channels peaking at different depths within the raining column. There are, however, more independent variables within raining clouds than there are channels in the observing system. The solution to this problem therefore requires additional assumptions or constraints. Radiative transfer calculations can be used to determine a brightness temperature vector, $\mathbf{T b}$, given a vertical distribution of hydrometeors represented by $\mathbf{R}$. An inversion procedure, however, is needed to find the hydrometeor profile, $\mathbf{R}$, given a vector $\mathbf{T b}$. The present retrieval method has its foundation in Bayes's theorem. In Bayes's formulation, the probability of a particular profile $\mathbf{R}$, given $\mathbf{T b}$ can be written as:

$$
\operatorname{Pr}(\mathbf{R} \mid \mathbf{T b})=\operatorname{Pr}(\mathbf{R}) \times \operatorname{Pr}(\mathbf{T b} \mid \mathbf{R}),
$$

where $\operatorname{Pr}(\mathbf{R})$ is the probability with which a certain profile $\mathbf{R}$ will be observed and $\operatorname{Pr}(\mathbf{T b} \mid \mathbf{R})$ is the probability of observing the brightness temperature vector, $\mathbf{T b}$, given a particular rain profile $\mathbf{R}$. The first term on the righthand side of Eq. (1) is derived using cloud-resolving models (CRM). While the models are only reviewed briefly, those aspects of the model that are important to the current discussion are described in detail in section 1a. To obtain the second term on the right-hand side of Eq. (1), radiative transfer schemes are used to compute the brightness temperatures corresponding to the CRM output. Together, the radiative transfer and the convolution of these temperatures to the appropriate sensor resolution scheme compose the forward modeling portion of the retrieval algorithm, which is covered in sec- tion $1 \mathrm{~b}$. The inversion scheme (section 1c) follows the description of the forward problem. Section 2 is devoted to a description of the algorithm improvements that have been undertaken in the last five years. Section 3 compares results from the operational algorithm to ground and complimentary spaceborne observations, and section 4 discusses the known shortcomings and future development strategies.

\section{a. The cloud-resolving models}

During the past two decades, convective-scale models have advanced sufficiently to study the dynamic and microphysical processes associated with mesoscale convective systems. The basic feature of these models is that they are nonhydrostatic and include an explicit representation of microphysical processes. The latter is critical in that it affects the computed brightness temperatures that must eventually be matched to the brightness temperatures observed by the satellite. GPROF currently uses two cloud-resolving models in its database, the Goddard Cumulus Ensemble Model (GCE) and the University of Wisconsin Nonhydrostatic Modeling System (UW-NMS). A description of the GCE model can be found in Tao and Simpson (1993). The cloud microphysics include a parameterized Kessler-type twocategory liquid water scheme (cloud water and rain), and parameterized Lin et al. (1983) three-category icephase schemes (cloud ice, snow, and graupel). The distributions of rain, snow, and graupel are taken to be inverse exponential with respect to the liquid equivalent diameter $D$ such that

$$
N(D)=N_{0} \exp (-\lambda D),
$$

where $N(D)$ is the number of drops of diameter between $D$ and $D+d D$ per unit volume, $N_{0}$ is the intercept parameter, and $\lambda$ is the slope of the distribution given by

$$
\lambda=\left(\frac{\pi \rho_{x} N_{0, x}}{\rho q_{x}}\right)^{0.25} .
$$

The intercept parameters, $N_{0, x}$, used in the GCE model for rain, snow, and graupel are 0.08, 0.04, and 0.04 $\mathrm{cm}^{-4}$, respectively. The density $\rho_{x}$ of rain, snow, and graupel are 1, 0.1 , and $0.4 \mathrm{~g} \mathrm{~cm}^{-3}$, respectively. Cloud water and cloud ice are assumed monodisperse with a diameter of $20 \mu \mathrm{m}$ and a density of 1.0 and $0.917 \mathrm{~g}$ $\mathrm{cm}^{-3}$, respectively. The density of air is given by $\rho$, while the mass density of the different hydrometeor species is given by $q_{x}$. The shapes of liquid and ice particles are not specified by the model. They are assumed spherical for the radiative transfer computations.

A stretched vertical coordinate (height increments from 220 to $1050 \mathrm{~m}$ ) with 31 grid points is used in order to maximize the resolution of the lowest levels, with the model top at $20 \mathrm{~km}$ for the simulations used by GPROF. The GPROF algorithm makes use of three separate simulations from this model. Two simulations are 
initialized using Tropical Ocean and Global Atmosphere Coupled Ocean-Atmosphere Response Experiment (TOGA COARE) soundings, while a third one uses Global Atmospheric Research Program (GARP) Atlantic Tropical Experiment (GATE) soundings. The first TOGA COARE simulation was run with a $1-\mathrm{km}$ spatial resolution over a $128 \mathrm{~km} \times 128 \mathrm{~km}$ domain. Eight model time steps starting at $30 \mathrm{~min}$ and ending at 240 min are used. The second simulation has a $3-\mathrm{km}$ spatial resolution over a $384 \mathrm{~km} \times 384 \mathrm{~km}$ domain. Six model steps are again used from 60 to $360 \mathrm{~min}$ in the simulation. The GATE model has a $1.5-\mathrm{km}$ horizontal resolution over a $96 \mathrm{~km} \times 96 \mathrm{~km}$ domain. Five model times, from 30 to $184 \mathrm{~min}$ in the simulation, are used.

The second model used is UW-NMS model described by Tripoli (1992a). Two simulations from this model are used in the GPROF database. These are the Cooperative Huntsville Meteorological Experiment $(\mathrm{COH}-$ MEX) simulation and the hurricane simulation as described at length by Panagrossi et al. (1998). Aside from differences in the dynamical assumptions in the model, the UW-NMS considers four classes of ice: graupel, pristine crystals, snow crystals, and aggregates that need to be treated differently in the generation of the GPROF cloud model database. A detailed description of these ice categories and their interaction may be found in Tripoli (1992b). Unlike the GCE, snow crystals as well as aggregates have a size-dependent density given by

$$
\rho=\frac{15}{(2 r)^{0.6}} \quad\left(\mathrm{~kg} \mathrm{~m}^{-3}\right),
$$

where the liquid equivalent radius $r$ is specified in centimeters. In the hurricane simulation, snow and aggregates are assumed to be a single category with a mean radius of $1.65 \mathrm{~mm}$. In the COHMEX simulation, these categories are treated separately, with snow having a mean radius of $0.5 \mathrm{~mm}$ and aggregates having a mean diameter of $1.65 \mathrm{~mm}$. The pristine ice category is assumed to have a uniform mass of $1.5 \times 10^{-9} \mathrm{~kg} \mathrm{~m}^{-3}$, and the density is assumed to be $0.22 \mathrm{gm} \mathrm{cm}^{-3}$. Graupel, like the GCE model, follows a Marshall and Palmer (1948) distribution but is assumed to have a density of $0.6 \mathrm{gm} \mathrm{cm}^{-3}$ in this model.

The COHMEX simulation was carried out with a 1$\mathrm{km}$ spatial resolution over a $50 \mathrm{~km} \times 50 \mathrm{~km}$ domain. Twelve time steps from 45 to $180 \mathrm{~min}$ in the simulation are used. The hurricane model has $3.3-\mathrm{km}$ spatial resolution over a domain of $205 \mathrm{~km} \times 205 \mathrm{~km}$. Time steps from 40 to $220 \mathrm{~min}$ are used. The time steps selected in all the models are intended to represent a good sampling of early, mature and decaying portions of each storm. The somewhat larger number of COHMEX time steps was intended to insure that enough models were selected from this simulation that had a more limited spatial domain.

\section{b. The radiative transfer model}

The observed microwave radiances at the top of the atmosphere originate partly at the earth's surface and partly from atmospheric constituents. The contribution from the earth's surface depends primarily upon the nature of the surface (i.e., water or land) and on the temperature of that surface. Atmospheric constituents such as oxygen, water vapor and cloud water act to absorb and emit upwelling radiation. Large precipitation drops further act to scatter upwelling radiation. Because of the varied, and often complex nature of each of these components, it is necessary to first understand the radiative properties of each of these components before attempting to understand the propagation of radiation through the medium.

The emissivity $\varepsilon$ of a surface at a particular frequency, polarization, and incidence angle is determined by the complex index of refraction of the surface as described by the Fresnel relations (Jackson 1962), as well as the surface roughness. Ocean and land surfaces must be treated separately. Over ocean, the index of refraction at the TMI frequencies depends primarily upon the surface temperature. In the current model, the salinity is taken to be constant at $34.5 \mathrm{ppb}$. The surface roughness is typically related to wind-driven waves and thus is related to the near-surface wind speed. While the effects of temperature and salinity are well understood, the effect of surface roughening is much more uncertain. In this study, the model of Wilheit (1979) is used to compute the ocean emissivity as a function of near-surface wind speed. While this model provides a satisfactory first-order correction to account for wind-induced roughening, it is recognized that this is an area of ongoing research that requires attention. However, it is not thought to be a dominant source of uncertainty at this time. Over land, the emissivity depends primarily upon the soil moisture but also on the soil and vegetation types. The surface emissivity is therefore assumed to be 0.9 corresponding to moderately dry, bare soil, and modified with a variable fraction of water-covered surface (between $0 \%$ and 20\%) to represent various soil moistures. The very indirect way in which soil moisture enters into the rainfall retrieval over land has not warranted improvement of this parameterization to date.

Among atmospheric absorbers of microwave radiation, water vapor, molecular oxygen, and cloud water must be considered. Water vapor has a weak pressurebroadened absorption line at $22.235 \mathrm{GHz}$ and a strong line at $183 \mathrm{GHz}$. The $22.235-\mathrm{GHz}$ line is of special significance since all sensors currently used for precipitation make a measurement near this line (SSM/I at 22.235 GHz; TMI at $21.3 \mathrm{GHz}$, and AMSR at 23.8 $\mathrm{GHz}$ ). Oxygen displays a strong complex of lines at 60 $\mathrm{GHz}$ as well as a single transition line at $118 \mathrm{GHz}$. The atmosphere is relatively clear in the window regions between these absorption lines. In this study, both the water vapor absorption and the oxygen absorption are 
calculated from Liebe et al. (1993). Nonprecipitating cloud particles of $20 \mu \mathrm{m}$ are specified in the cloud models. This dimension is much smaller than typical wavelengths under consideration $(3.5 \mathrm{~mm}$ to $3 \mathrm{~cm})$, thus permitting the use of the Rayleigh approximation. The absorption cross section in this case depends only upon the dielectric constant of the liquid and upon the third power of the diameter of the cloud droplets. Thus, the absorption of the cloud water is simply proportional to the total mass of cloud water and is independent of the droplet size distribution. Scattering is negligible in this limit.

As cloud drops coalesce into raindrops, their dimensions can get comparable to microwave wavelengths and the Rayleigh approximation becomes invalid. If particles are assumed spherical, Mie theory may be employed. For shapes other than spheres, solutions like the Extended Boundary Condition Method (Barber and Hill 1990), or the discrete dipole approximation (Draine and Flatau 1988) must be employed. The difficulties introduced by any of these methods are threefold. The first is due to scattering parameters exhibiting resonance features that effectively increase the scattering efficiency beyond the third power of the drop diameter. This causes the volume scattering characteristics to depend upon the drop size distribution. The second difficulty introduced by the larger size parameters is that scattering becomes important. In the case of $85 \mathrm{GHz}$, ice scattering from precipitation-size hydrometeors becomes the dominant characteristic. Last, it must be mentioned that computationally these codes are all far more intensive than the closed-form expression of the Rayleigh approximation. The operational version of GPROF uses Mie theory to compute all single particle scattering properties. This, as noted above, implies that all particles are assumed spherical-even when this is known not to be the case. Assuming spherical particles for rainfall introduces errors in the extinction cross section and asymmetry parameter that can account for up to $4 \mathrm{~K}$ at very heavy rainfall rates at $19 \mathrm{GHz}$, with smaller maximum errors at $10 \mathrm{GHz}$ and slightly larger errors at 37 and $85 \mathrm{GHz}$. Ice particles are more complicated yet, with unknown particle sizes, densities, and shapes all affecting the upwelling brightness temperatures. These are currently also treated as spheres despite evidence that oriented ice particles can cause polarization differences of up to $10 \mathrm{~K}$ in stratiform regions associated with strong convection. Last, the effect of melting particles is currently not considered by GPROF because, once again, there is not enough observational evidence to suggest how the bright band should be modeled at this time. Recent studies by Bauer et al. (1999) and Olson et al. (2001a) begin to address this issue.

Once the radiative properties of the surface and atmosphere are known or assumed, it is straightforward to apply radiative transfer techniques to compute the brightness temperatures emerging at the top of the atmosphere. A one-dimensional Eddington approximation is currently being used in the operational version of GPROF. The details of the Eddington approximation, as well as its accuracy (1-2 K for the present application), are summarized by Kummerow (1993). While one-dimensional models can be constructed to better account for the inhomogeneity of variability in adjacent cloud model profiles and three-dimensional methods have been available for a number of years now (e.g., Petty 1994; Roberti et al. 1994), these are not used in the operational version. Sensitivity tests have shown only minor impacts on the retrieved rainfall $(\sim 1 \%)$, and it was felt that the faster one-dimensional methods would be more practical at this time.

When high-resolution brightness temperature fields have been calculated using either plane parallel or Monte Carlo methods, it is necessary to simulate the radiances as they would be measured from a downviewing microwave sensor. For simplicity, GPROF uses the published resolution of each channel (as defined by the 3$\mathrm{dB}$ gain) to determine the number of cloud model grid elements that must be averaged to best match the resolution of each channel. Sensitivity studies show that the more precise convolution with the exact antenna gain function has little effect upon the retrieved rainfall rates. The effects of deconvolution schemes that increase the spatial resolution of the observed brightness temperatures at the expense of some additional noise (Robinson et al. 1992; Farrar and Smith 1992) have not been examined in the context of GPROF.

\section{c. The retrieval procedure}

The retrieval procedure follows the Bayesian approach outlined in Kummerow et al. (1996). The vector $\mathbf{x}$ is used to represent all of the physical quantities to be retrieved in the inversion method, and the vector $\mathbf{y}_{0}$ represents the set of available sensor observations. Following Lorenc (1986), it is assumed that the "best" estimate of $\mathbf{x}$, given the set of observations $\mathbf{y}_{0}$, is the expected value,

$$
E(\mathbf{x})=\iint \cdots \int \mathbf{x} p d f(\mathbf{x}) d \mathbf{x},
$$

where the probability density function $\operatorname{pdf}(\mathbf{x})$ is proportional to the conditional probability that $\mathbf{x}$ represents the true earth-atmosphere state, $\mathbf{x}_{\text {true }}$, given that $\mathbf{y}$ is equal to the observed $\mathbf{y}$ :

$$
\operatorname{pdf}(\mathbf{x}) \propto P\left(\mathbf{x}=\mathbf{x}_{\text {true }} \mid \mathbf{y}=\mathbf{y}_{0}\right) .
$$

The expected value $E(\mathbf{x})$ in Eq. (5) is known as the minimum variance solution for $\mathbf{x}$. The multiple integral signs in Eq. (5) indicate integration over all dimensions of the state vector $\mathbf{x}$. Using Bayes's theorem (again following Lorenc 1986), Eq. (6) may be rewritten as

$$
\begin{aligned}
\operatorname{pdf}(\mathbf{x}) & \propto \mathbf{P}\left(\mathbf{y}=\mathbf{y}_{0} \mid \mathbf{x}=\mathbf{x}_{\text {true }}\right) \times \mathbf{P}\left(\mathbf{x}+\mathbf{x}_{\text {true }}\right) \\
& \propto \mathbf{P}_{\mathrm{OS}}\left|\mathbf{y}_{0}-\mathbf{y}_{s}(\mathbf{x})<\varepsilon\right| \times \mathbf{P}_{\mathrm{AS}}\left(\mathbf{x}=\mathbf{x}_{\text {true }}\right),
\end{aligned}
$$


where $\mathbf{P}_{\mathrm{OS}}$ is equivalent to the probability that the set of observations $\mathbf{y}_{0}$ deviate from the set of simulated observations $\mathbf{y}_{s}(\mathbf{x})$ by a certain amount, given the earth-atmosphere state $\mathbf{x}$, and $\varepsilon$ is the uncertainty introduced by the forward modeling assumptions discussed in section $2 \mathrm{~b}$. In future discussions, $\mathbf{P}_{\mathrm{OS}}$ will be called the probability of the observational deviation, and $\mathbf{P}_{\mathrm{AS}}$ is the a priori probability that $\mathbf{x}$ is the true state of the earth-Atmosphere.

If it is further assumed that the errors in the observations and the simulated observations are Gaussian, uncorrelated, and with zero mean, then the probability of observational deviation can be expressed as

$$
\begin{aligned}
\mathbf{P}_{\mathrm{OS}}\left[\mathbf{y}_{0}-\mathbf{y}_{s}(\mathbf{x})\right] & \\
\propto \exp \{ & -0.5\left[\mathbf{y}_{0}-\mathbf{y}_{s}(\mathbf{x})\right]^{\mathrm{T}} \times(\mathbf{O}+\mathbf{S})^{-1} \\
& \left.\times\left[\mathbf{y}_{0}-\mathbf{y}_{s}(\mathbf{x})\right]\right\},
\end{aligned}
$$

where $\mathbf{O}$ and $\mathbf{S}$ are the observation and model error covariance matrices, respectively. Substituting for $\mathbf{P}_{\mathrm{OS}}$ in Eq. (7) using Eq. (8) and then using the resulting expression to substitute for pdf in Eq. (5), the final expression for the minimum variance solution is

$$
E(\mathbf{x})=\iint \cdots \int \frac{\mathbf{x} \exp \left\{-0.5\left[\mathbf{y}_{0}-\mathbf{y}_{s}(\mathbf{x})\right]^{\mathrm{T}}(\mathbf{O}+\mathbf{S})^{-1}\left[\mathbf{y}_{0}-\mathbf{y}_{s}(\mathbf{x})\right]\right\}}{\mathbf{A}} \mathbf{P}_{\mathrm{AS}}\left(\mathbf{x}=\mathbf{x}_{\text {true }}\right) d \mathbf{x},
$$

where $\mathbf{A}$ is the normalization factor

$$
\begin{aligned}
& \mathbf{A}=\iint \cdots \int \exp \{-0.5\left[\mathbf{y}_{0}-\mathbf{y}_{s}(\mathbf{x})\right]^{\mathrm{T}}(\mathbf{O}+\mathbf{S})^{-1} \\
&\left.\times\left[\mathbf{y}_{0}-\mathbf{y}_{s}(\mathbf{x})\right]\right\} \mathbf{P}_{\mathrm{AS}}\left(\mathbf{x}=\mathbf{x}_{\text {true }}\right) d \mathbf{x} .
\end{aligned}
$$

The approach utilized in the present study is to make an approximate evaluation of the integral form of the minimum variance solution, Eq. (9). A sufficiently large database of atmospheric profiles and associated brightness temperatures is generated using output of the cloudresolving models (section 2a) in conjunction with the forward passive microwave radiometer model (section $2 b$ ). Using the large atmospheric profile-radiative database, the integral form of the minimum variance solution, Eq. (9) can be approximated by

$$
\hat{E}(\mathbf{x})=\sum_{j} \mathbf{x}_{j} \frac{\exp \left\{-0.5\left[\mathbf{y}_{0}-\mathbf{y}_{s}\left(\mathbf{x}_{j}\right)\right]^{\mathrm{T}}(\mathbf{O}+\mathbf{S})^{-1}\left[\mathbf{y}_{0}-\mathbf{y}_{s}\left(\mathbf{x}_{j}\right)\right]\right\}}{\mathbf{A}}
$$

where $\mathbf{A}$ is the normalization factor:

$$
\begin{aligned}
& \mathbf{A}=\sum_{j} \exp \{-0.5\left[\mathbf{y}_{0}-\mathbf{y}_{s}\left(\mathbf{x}_{j}\right)\right]^{\mathrm{T}}(\mathbf{O}+\mathbf{S})^{-1} \\
&\left.\times\left[\mathbf{y}_{0}-\mathbf{y}_{s}\left(\mathbf{x}_{j}\right)\right]\right\}
\end{aligned}
$$

The integrals in Eqs. (9) and (10) are replaced by the summations in Eqs. (11) and (12) over all model simulated profiles $\left(\mathbf{x}_{j}\right)$ in the atmosphere-radiative model database. Here the main assumption is that profiles in the model database occur with nearly the same relative frequency as those found in nature, or at least with the same frequency as those found in the region where the inversion method is to be applied. Under this assumption the weighting by $\mathbf{P}_{\mathrm{AS}}\left(\mathbf{x}=\mathbf{x}_{\text {true }}\right)$ in the integral form [Eq. (9)] is represented simply by the relative number of occurrences of a given profile type $\mathbf{x}_{j}$ in the summation [Eq. (11)]. Since the profiles are simulated using a model that incorporates most relevant physical processes of the earth and atmosphere, the relative abundance of profiles of a certain type should be roughly the same as those of naturally occurring profiles if 1) the atmospheric model is used to simulate cloud development over the range of environments that are observed in the region of interest; 2) each cloud model simulation is sampled at regular time intervals, such that no particular stage of cloud or cloud system development is favored over another; and 3) the model is sufficiently complete as to yield realistic simulations. The degree to which a breakdown of these assumptions can cause random and systematic errors is a topic of current research.

\section{Algorithm improvements}

Figure 1 shows a comparison of rainfall rates derived before (version 4) and after (version 5) improvement of the GPROF algorithm. As can be seen from Fig. 1, the general patterns are quite similar but the latest version has much better defined convective areas and much less rainfall in the stratiform regions between rain bands than its predecessor. Qualitatively, this agrees much better with the rainfall structure derived from the precipitation radar (bottom panel). Validation of rainfall rates and accumulations, as will be seen in the subsequent section, yields often contradictory information. Changes to the 
algorithm were therefore motivated primarily by physical arguments rather than agreement with validation data. A list of improvements, as well as the rationale for undertaking these improvements, is presented next.

\section{a. Improved freezing level over oceans}

While already incorporated in version 4 of the algorithm, a change in the freezing-level height determination is included here because it represents a significant change from the algorithm description published previously. Early versions of the GPROF algorithm (pre-1998) made use of climatological freezing level data in order to choose from the appropriate subset of a priori cloud models (those matching the presumed freezing level). This caused the algorithm to significantly overestimate the rainfall at mid- and high latitudes. An example of this overestimation occurred during the Third WetNet Precipitation Intercomparison Project (PIP-3) intercomparison (Adler et al. 2000). The cause for this overestimation was the very low freezing level prescribed by the climatological data at high latitudes during winter conditions. Comparisons between radar-derived freezing levels and those prescribed by climatological data were used to verify that freezing levels within raining systems were often significantly higher than that prescribed by climatological data. The freezing-level height determined from the microwave sensor itself, as described by Wilheit et al. (1991), and subsequently validated (Bellows 1999) was therefore implemented. The modified algorithm reduced the artificially high rainfall at high latitudes to values that were comparable to both the emission algorithm described earlier as well as available climatological datasets of rainfall.

\section{b. Convective-stratiform discrimination}

The most significant improvement of GPROF, as mentioned at the outset, is an improved treatment of the convective-stratiform separation by the algorithm. This classification is done prior to the inversion. The area fraction of convection within the TMI footprint, derived from the brightness temperature data, is then treated as an additional parameter that needs to be matched in the Bayesian solution. The method used to calculate the area fraction of convection within a TMI footprint draws upon measures of the local horizontal gradients (or texture) of brightness temperatures as well as the polarization of $85.5-\mathrm{GHz}$ scattering signatures; see Olson et al. (2001b). To date, the convective-stratiform discrimination is applied only over oceans where the true Bayesian scheme can be applied. There is some evidence that it is also a useful parameter over land, but studies are still ongoing.
Dec. 19, 1997 (336)
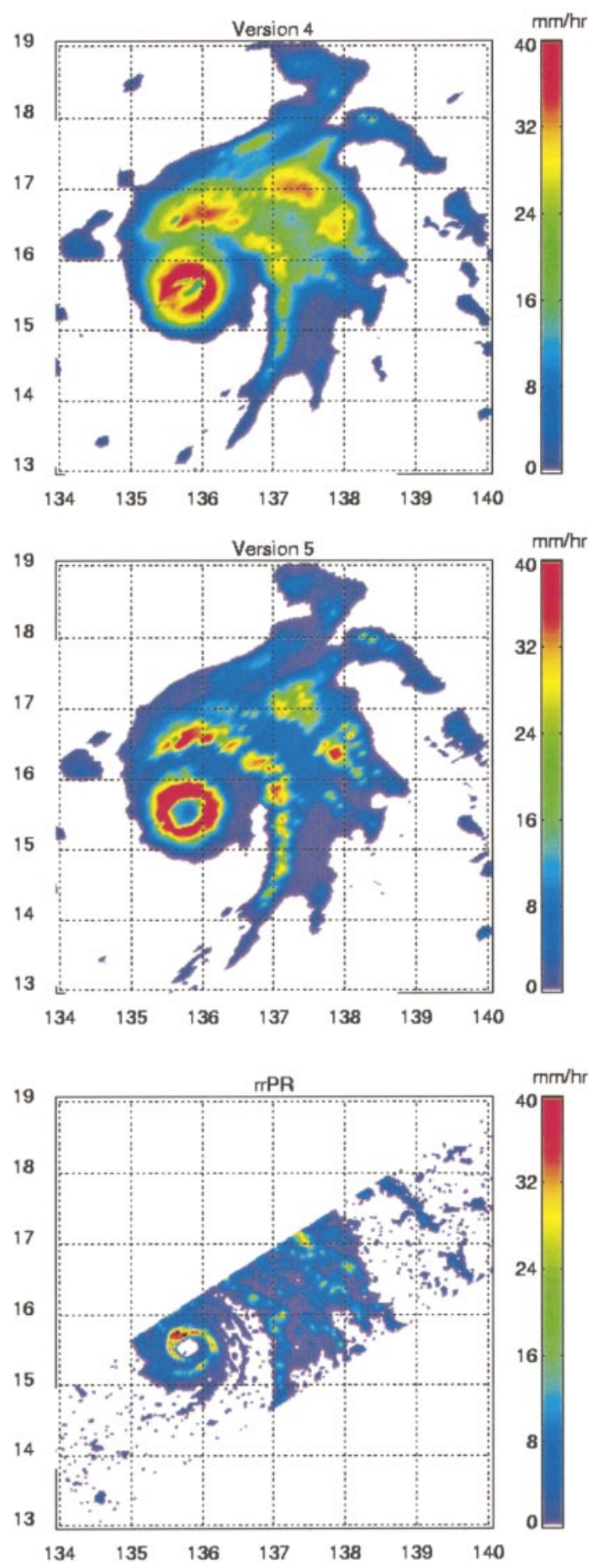

FIG. 1. Comparison of the TRMM GPROF algorithms: (top) the at-launch algorithm (version 4), (middle) the current product (version 5), and (bottom) current PR estimated rainfall. 


\section{1) Texture-based estimates of Convective} FRACTION

The basis of this technique is the common observation that, in convective regions, which are characterized by locally strong updrafts and downdrafts, the horizontal variations of liquid and ice-phase precipitation are relatively large. In contrast, stratiform regions are characterized by relatively weak and horizontally uniform updrafts and downdrafts, and these are associated with fairly uniform distributions of precipitation.

The difference of the horizontal texture of convective and stratiform precipitation fields was first exploited by Churchill and Houze (1984), who identified convective centers in horizontal radar scans using the local maximum of reflectivity as an indicator. Similarly, Hong et al. (1999) related local maxima of emission and scattering in SSM/I brightness temperature imagery (associated with local maxima of liquid and ice-phase precipitation, respectively) to the areal fraction of convection within a footprint. The method was calibrated using collocated observations from the TOGA COARE shipboard radars. The relationships between emission and scattering texture and convective fraction were generalized to observations of the TMI by synthesizing TMI radiances using the radar data in combination with cloud-resolving model simulations.

\section{2) Polarization-Based estimates of CONVECTIVE FRACTION}

A second method for estimating convective fraction from passive microwave data was spurred by analyses of SSM/I observations by Spencer et al. (1989) and Heymsfield and Fulton (1994a,b). These authors found significant differences, on the order of $5 \mathrm{~K}$ or greater, between the vertically and horizontally polarized 85.5$\mathrm{GHz}$ brightness temperatures in stratiform rain regions over land, whereas regions of strong convection were nearly unpolarized at $85.5 \mathrm{GHz}$. Although the physical basis of these polarization differences has not been verified, the aforementioned authors hypothesized that precipitation-sized ice particles such as snow or aggregates would tend to become oriented as they fall through the relatively weak updrafts or downdrafts of stratiform rain regions, resulting in preferential scattering in the horizontal polarization. The more turbulent, vigorous updrafts of convective regions would cause ice hydrometeors to lose any preferred orientation, leading to similar scattering signatures in both polarizations. This hypothesis is supported by recent radiative modeling studies by Petty and Turk (1996), Schols et al. (1997), and Haferman (1999).

Polarization signatures in SSM/I observations were related to the areal fraction of convection within a footprint by Olson et al. (1999), who used these to constrain GPROF retrievals of precipitation and latent heating. The method was later refined to account for the increase of polarization with scattering at $85.5 \mathrm{GHz}$ in stratiform areas (Olson et al. 2001b).

\section{3) Merger of techniques}

The texture and polarization-based estimates of convective area fraction within a TMI footprint are merged by taking a weighted average of the estimates. The weighting is specified as the inverse of the error variance of each of the estimates, which allows for an optimal combined estimate (Daley 1991). An estimate of the error variance of the texture-based convective fraction is based upon previous intercomparisons of TMI-based convective fractions and coincident ground-based radar observations. The authors of this study found greater uncertainty in convective fraction estimates when there was a mixture of convective and stratiform precipitation within the radiometer footprint, while in the middle of largely convective or stratiform regions the uncertainty was reduced. From theoretical considerations, the error of the polarization-based convective fraction estimate is inversely proportional to the $85.5-\mathrm{GHz}$ scattering depression. Formulas for the convective fraction estimates, error variances, and the combined estimate of convective area fraction may be found in Olson et al. (2001b).

\section{4) Addition of the “CONVective PRofile" to THE SEARCH CRITERIA}

One shortcoming of earlier versions of GPROF that became apparent immediately after the launch of the TRMM satellite was the artificially large extent of heavy precipitation surrounding convective cells. This is apparent in Fig. 1. In contrast, radar observations of organized precipitation systems typically show a strong gradient of rain intensity, with the highest rain rates associated with convection but falling off quickly in the transition and "purely" stratiform regions.

The apparent positive bias of early GPROF rain rates in regions surrounding convection was attributed to two factors. First, theoretical studies indicate greater microwave emission from horizontally uniform precipitation fields than from horizontally inhomogeneous fields, for a given footprint-averaged rain rate. This is known as the "beamfilling" problem and has been discussed in the literature (Wilheit et al. 1991). Because of the aliasing caused by the inhomogeneity of rainfall within a satellite footprint, the mean rain rate associated with a given set of brightness temperatures in the GPROF cloud model database tends to be much lower for the subset of simulated stratiform footprints relative to the mean rain rate associated with the subset of convective footprints. Since the database contains a mixture of simulated convective and stratiform footprints, a search based upon brightness temperature data alone would tend to yield a positive bias of rain estimates in stratiform regions and a negative bias of rain estimates in convection. 


\section{GSCAT2 Screen}

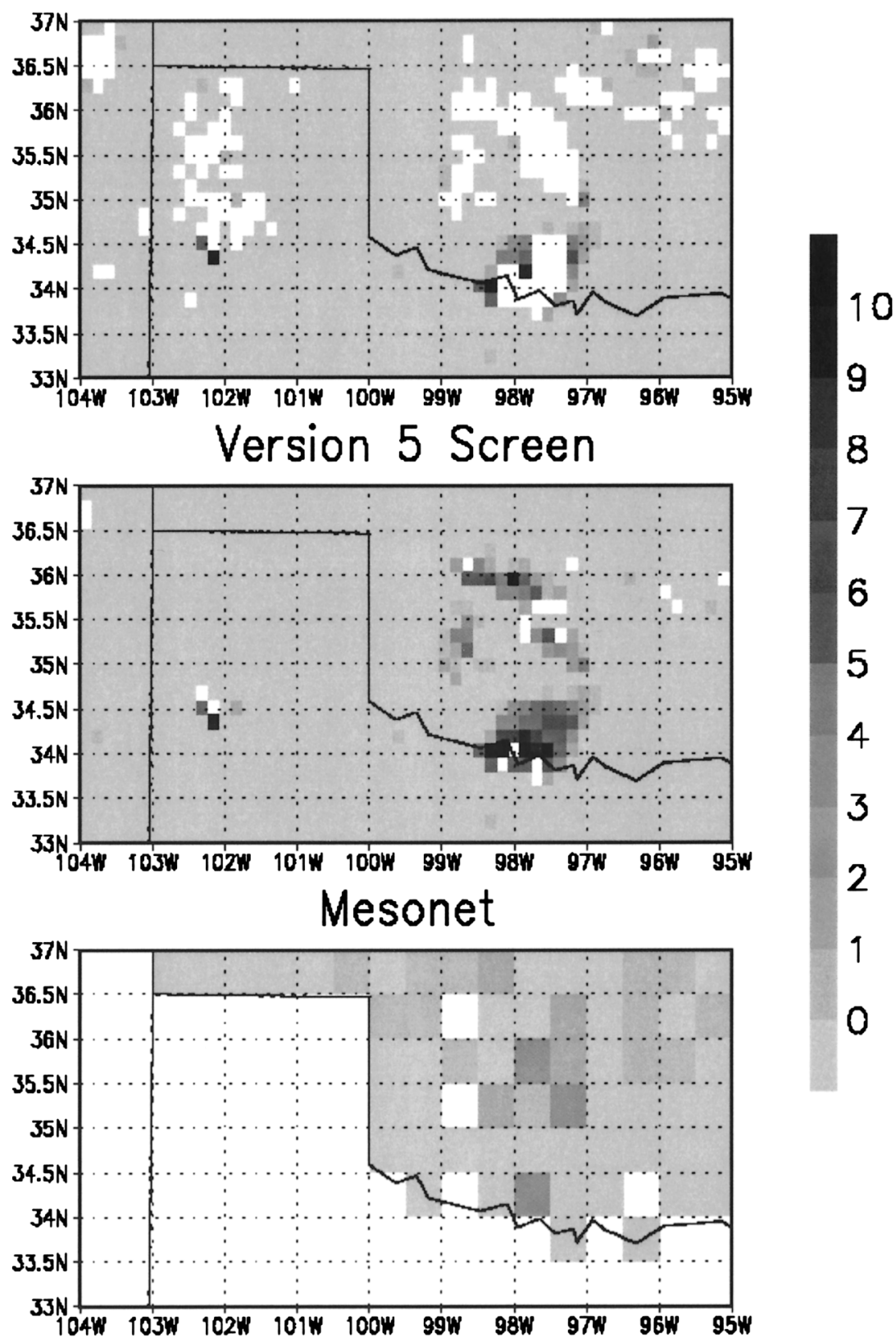

FIG. 2. Comparison of 30-min mean mesonet estimates with estimates from a corresponding TMI overpass around 0815 UTC 12 Mar 1999. Rainfall rates are in millimeters per hour.

A second factor is related to the statistical distribution of rain rates in the GPROF database. Most of the cloud model simulations in the current database favor convection; that is, horizontally extensive stratiform rain regions are not represented in proportion to their occurrence in nature. This means that stratiform rain events represented in the cloud model database typically occur in close proximity to convection. The reasons for this "convective bias" may be due to deficiencies in the current cloud model microphysical schemes or to the fact that the environmental forcing prescribed in the model simulations (e.g., vertical wind shear and the nature of the dynamic forcing) is not favorable for the development of extended stratiform regions. The net effect of this statistical bias is that even if the search routine in GPROF is constrained to consider only simulated stratiform footprints in the database, these will likely come from regions in close proximity to convection where rain rates are typically far less homogeneous than those at greater distances from convection. 
To help to reduce the aforementioned biases associated with stratiform rain, a filter is applied to derive the horizontal profile of maximum convective area fraction within three scan lines (about $40 \mathrm{~km}$ ) of the footprint being analyzed by GPROF (see Olson et al. 1999). The search method in GPROF is also modified to identify simulated footprints in the cloud model database that match not only the observed radiance data but also the observed profile of maximum convective fraction. Therefore, if a stratiform footprint is analyzed by GPROF, and the nearest "convective" footprint in the TMI swath is $30 \mathrm{~km}$ distant, then the search routine in GPROF is modified to look for a similar stratiform footprint in the cloud model database. Mathematically, the additional search criteria take the form of an additional constraint term in the arguments of the exponentials in Eqs. (11) and (12).

The result of this modification to GPROF is a significant decrease of precipitation in stratiform areas, especially in those areas far from convection. The resulting vertical hydrometeor profiles also show the correct behavior, with a general absence of cloud liquid water and evidence of rain evaporation below the freezing level in stratiform regions.

\section{c. Use of emission and scattering indices}

The Bayesian methodology requires that each channel be weighted by the inverse of the variance or uncertainty in that channel. The uncertainty is the sum of the uncertainty in the measurement (sensor noise, $\mathrm{NE} \Delta \mathrm{T}$ ) plus the uncertainty in the forward model. The latter is not well defined at this time, as it depends upon errors in the cloud dynamical model, the radiative transfer methods, or linkages between them (e.g., the spherical drop assumption). Version 4 of GPROF assigned equal weights to all sensor channels. Version 5 uses the polarization-based emission and scattering indices as defined by Petty (1994). The indices have the advantage in that they isolate the signal coming from the rain cloud itself from the background variability and they are monotonic functions of the rainfall emission or ice scattering intensity. They also decouple the effects of scattering from emission-attenuation effects, thus facilitating the discrimination of frozen hydrometeor from liquid precipitation and cloud. As such, they are better related to the uncertainties needed by the inversion method that should lead to improvements in the future. At present, however, little progress has been made in defining the uncertainties. The emission indices and the convective-stratiform (C-S) classification vary between 0 and 1 and are given equal weight. Scattering indices measure the net scattering signal coming from the cloud and vary between zero, no scattering, and $\sim 150 \mathrm{~K}$ in very strong thunderstorms. Scattering indices are normalized by a factor of 100 , so that scattering indices have approximately the same magnitude as the other indices. The covariance matrix $[\mathbf{O}+\mathbf{S}$ in Eq. (11)] in this formulation is therefore replaced by a diagonal 7 $\times 7$ matrix for the four emissions, two scattering and the convective-stratiform index. Because cross correlations among indices are not well understood, particularly from the modeling perspective, they are currently ignored. The value of the matrix elements representing the brightness temperature uncertainties is currently set at an equivalent of approximately $8 \mathrm{~K}$ for all elements. Work is under way to improve upon this initial framework, but the value of $8 \mathrm{~K}$ was chosen empirically as the smallest value before the algorithm begins to find no matches between observations and database simulations and thus becomes artificially noisy.

\section{d. Use of the NESDIS operational rainfall relationship over land}

The TMI GPROF land rainfall algorithm was merged with the National Environmental Satellite, Data, and Information Service (NESDIS) operational algorithm. While version 4 routines are still used to quality control data, the NESDIS operational rainfall relations were implemented in version 5. Since rainfall over land depends upon the scattering signature only, not enough radiometric information exists to justify the physical inversion carried out over oceans. As such, rainfall relations over land need to be calibrated using independent measures of precipitation. In addition, a great deal of care must be used to screen a multitude of cold surfaces, which, under the right conditions, can be easily misinterpreted as rainfall. Implementing the broadly used NESDIS algorithm over land was intended to reduce the number of parallel algorithms in order to concentrate the improvement efforts. Incorporating the algorithm into the GPROF structure was done in order to facilitate access to rainfall products for users needing rainfall over both land and ocean.

\section{1) RAINFALl RELATION}

GPROF was modified to produce rainfall rates similar to those of the NESDIS operational rainfall algorithm (Ferraro 1997). The basis of the NESDIS algorithm comes from the work of Grody (1991), who developed a global, empirical, scattering index (SI) using the 19-, $22-$, and $85-\mathrm{GHz}$ vertically polarized SSM/I channels. Ferraro and Marks (1995) calibrated the SI with groundbased radar rainfall estimates to produce instantaneous rain rates. The form of the rainfall rate estimation equation is

$$
\mathrm{RR}=\left(0.005 \text { 13) } \times(\mathrm{SI})^{1.9468},\right.
$$

where RR is in millimeters per hour, and SI is defined by:

$$
\begin{aligned}
\mathrm{SI}= & \left(451.9-0.044 \mathrm{~Tb}_{19 \mathrm{~V}}-1.775 \mathrm{~Tb}_{22 \mathrm{~V}}\right. \\
& \left.+0.00575 \mathrm{~Tb}_{22 \mathrm{~V}}^{2}\right)-\mathrm{Tb}_{85 \mathrm{~V}}
\end{aligned}
$$


where $\mathrm{Tb}$ denotes the brightness temperature and the subscript refers to the appropriate channel.

The NESDIS algorithm was reconstructed within the GPROF framework by restricting the models in the a priori database to only those that fit the predetermined regression line established in Eqs. (13) and (14). An advantage of this procedure is that once the regression is established, it can easily be applied to other sensors. The relations of Eqs. (13) and (14) were derived for the SSM/I sensor. The appropriate TMI database was then computed using the radiative transfer simulations with the same cloud model output as for the SSM/I database, accounting for the changes in frequency and resolution between the two sensors. Because the differences between the brightness temperatures at 21 and $22 \mathrm{GHz}$ over land are very small, these can be interchanged when adopting the NESDIS algorithm for use with the TMI.

The difference between the $21 \mathrm{~V}$ and the $85 \mathrm{~V}$ brightness temperatures is used to compare the satellite brightness temperatures with those of the vertical hydrometeor profile database. In GPROF version 4, the only criterion used to select profiles was the horizontally polarized 85 $\mathrm{GHz}$. While it is generally not beneficial to use lowfrequency channels over land because of the variable emissivity of the land surface, it is possible to take the temperature of the land surface into account by using a combination of low-frequency channels to determine the background temperature field. The NESDIS algorithm uses a combination of the 19- and 21-GHz channels to accomplish this goal as seen in Eq. (14). The vertical polarization is used to reduce the sensitivity to emissivity changes over land areas (Grody 1991).

\section{2) IMPROVED COLD SURFACE SCREENING}

In addition to modifying the estimated rainfall rates, however, a new procedure was developed to better classify ("screen") each land pixel as "raining," "nonraining," or unclassifiable ("indeterminate"). GPROF version 4 used the screening methodology of the Goddard scattering algorithm GSCAT2 (Adler et al. 1994). As shown in Ferraro et al. (1998), there are many viable screening techniques available for use with the SSM/I. The new algorithm incorporates the best features of the NESDIS and GSCAT2 screening methodologies.

SSM/I data were used for a comparison of the NESDIS and GSCAT2 screening procedures. The conclusions from this comparison should apply to both the SSM/I and TMI algorithms, because both simulated and actual data were used to show that the slight differences in frequency do not result in significantly different brightness temperatures for the SSM/I and TMI. The GSCAT2 screening procedure appears to be more globally robust, because there are regions and times when the NESDIS algorithm incorrectly classifies melting snow as rain, while the GSCAT2 screening results in an indeterminate classification. Thus, the GSCAT2 methodology with a new postprocessing procedure is used in version 5 .

Visual inspection of estimated rainfall fields shows that GSCAT2 often makes indeterminate classifications next to legitimate rainfall areas, which suggests that pixels with rain are classified as indeterminate. Sometimes the indeterminate pixels are even surrounded by rain. To help to resolve these situations, a postprocessing step that uses spatial information to reclassify indeterminate pixels was added. This postprocessing consists of searching the vicinity of the indeterminate pixels and if there is a consensus of either rain or no-rain classifications in the vicinity, the indeterminate pixels are reclassified to match the surrounding pixels.

Figure 2 illustrates the benefit of using spatial information to reclassify indeterminate pixels. The figure clearly shows that large areas that were previously classified as indeterminate are now classified as raining. This agrees qualitatively with the Oklahoma Mesonet data (Brock et al. 1995). The mesonet consists of 113 rain gauges throughout Oklahoma. The rain gauge data within each $0.5^{\circ}$ are averaged to produce the means shown in the figure. No estimates were made in four grid boxes because of the lack of rain gauges at these locations. The mesonet data support the version-5 nonzero rain estimates that are not made using the GSCAT2 screen because of indeterminate classifications.

A sample comparison of instantaneous rainfall estimates from SSM/I and TMI overpasses occurring at approximately the same time on 8 January 1999 is shown in Fig. 3. As with other days tested, there is very close correspondence between the NESDIS SSM/I (SSM/I SI) algorithm estimates produced from Eqs. (13) and (14) (top panel), the SSM/I GPROF rainfall estimates (middle panel), and the TMI GPROF (version 5) estimates (bottom panel). In addition, the screens developed using SSM/I data show even better performance with the TMI data, because there are fewer indeterminate classifications. This is due to the reduced inhomogeneity within the smaller TMI fields-of-view.

\section{Comparisons with independent rainfall data}

Because of the difference in the underlying physics of the GPROF algorithm over oceans and land, comparisons with other data sources are carried out independently for the two background types. The comparisons, as will be seen, yield mixed results, with no clear indication that there is, or is not, any systematic problem with the rainfall products.

\section{a. Rain gauge data}

\section{1) Pacific Atoll data}

Rain gauges located on Pacific atolls are used for comparisons with GPROF version-5 results. The area covered by the atolls extends from approximately $25^{\circ} \mathrm{S}$ 


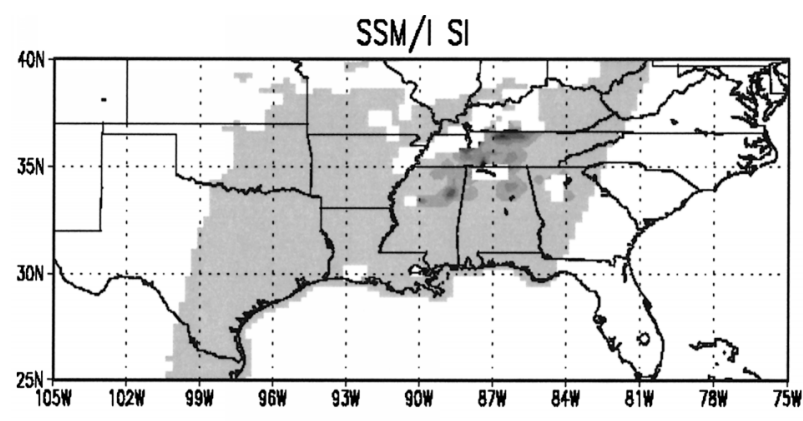

SSM/I GPROF

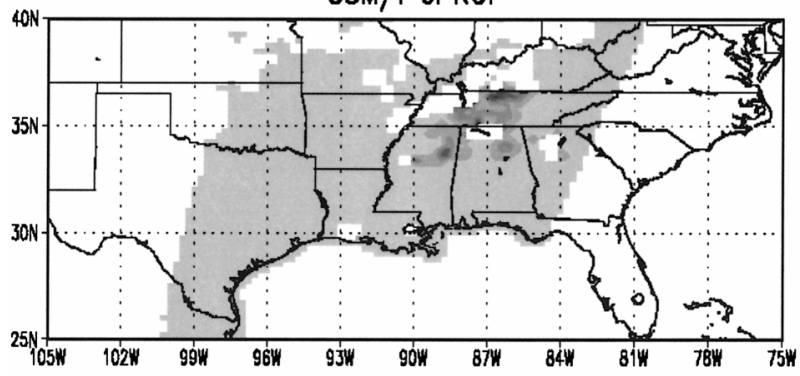

TMI GPROF

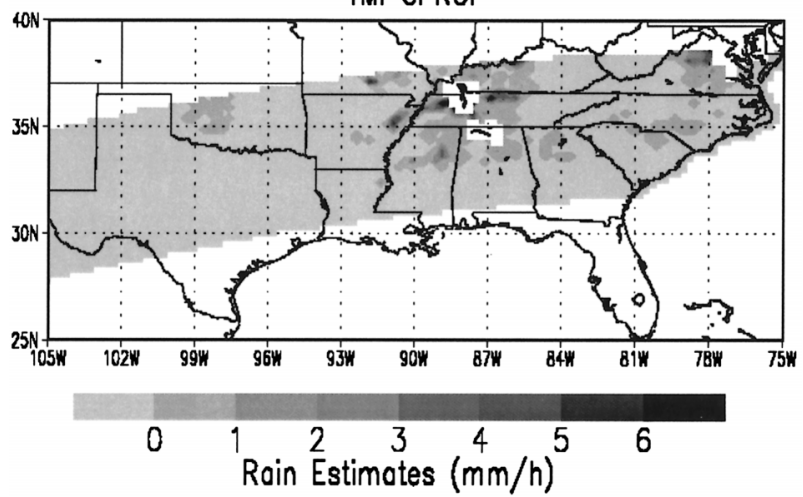

FIG. 3. Instantaneous rainfall estimates $\left(\mathrm{mm} \mathrm{h}^{-1}\right)$ from SSM/I and TMI overpasses occurring at nearly the same time on 8 Jan 1999. The estimates are from the following algorithms: (top) NESDIS SSM/ I, (middle) the new SSM/I GPROF, and (bottom) the new TMI GPROF.

to $15^{\circ} \mathrm{N}$ and from $130^{\circ} \mathrm{E}$ to $130^{\circ} \mathrm{W}$. While the number of quality-controlled gauges varies from month to month, the numbers vary between 20 and 40. Only 34 grid boxes (depending upon the number of gauges) typically contain more than one gauge in any given $2.5^{\circ}$ grid box. Details of the gauge network and the quality control procedures can be found in Morrissey et al. (1995). The sources of error are multiple. From the satellite side, the algorithm errors depend both on the sampling errors as well as the retrieval errors. Sampling errors for satellite platforms are primarily a function of the revisit times and rainfall frequency, which is well related to rainfall accumulation in the Tropics. As such, locations with higher rainfall amounts should have smaller relative errors. Fortunately, this error is random and for the time interval considered here should produce no overall bias. From the rain gauge perspective, one must allow for three possible error sources: 1) rainfall may not be homogeneous over the $2.5^{\circ}$ grid box the rain gauge is supposed to represent-while this may sound like a simple assumption, the movement of the ITCZ may at times make this assumption less than ideal for individual gauges; 2) the rain gauges may, at times, operate improperly-with few rain gauges, it can be difficult to apply perfect quality control proceduresand thus, while great care is taken of these gauges, there is no guarantee that they are all estimating properly, which could lead to an underestimate by the gauge network; and 3) the atolls themselves are assumed not to be enhancing convection and thus providing higherthan-average rainfall relative to the surrounding grid box.

Figure 4a shows a scatter plot of the satellite accumulation over 30 -day, $2.5^{\circ}$ grids, versus the 30 -day rain gauge average when all atoll gauges are considered. Figure $4 \mathrm{~b}$ shows the same results, but considering only those $2.5^{\circ}$ grid boxes that contain at least two atoll gauges. The scatter of points is due primarily to the sampling difference between the two data sources. Biases would indicate fundamental problems with one dataset or the other. In this case, biases are small (-9\%, GPROF underestimates) when all gauges are used, and reversing to $+6 \%$ (GPROF overestimates) when only grid boxes with two gauges are considered. Correlations are high in both cases, namely, 0.85 for all gauges and 0.91 for grid boxes with two or more rain gauges.

\section{2) GPCC RAIN GAUGES}

Figure 5 shows a scatterplot of the GPROF version5 rainfall in comparison with rain gauge data collected and analyzed by the Global Precipitation Climatology Centre (GPCC) of the Deutscher Wetterdienst. The GPCC begins by interpolating available rain gauge data into a $0.5^{\circ}$ latitude-longitude grid. These points are then averaged over a $2.5^{\circ}$ grid. Rudolph et al. (1996) give a detailed description of the procedure. The rain gauge product incorporates approximately 6700 rain gauges, but the quality of the estimate varies depending upon the number available in any given grid box. The numbers vary from less than 1 gauge per $2.5^{\circ}$ grid in some tropical locations to as many as 50 in the highly populated industrial countries.

Rain gauge data represent the continuous accumulation over a few square centimeters as compared with the large area averages from approximately 30 instantaneous overpasses by the TRMM satellite. A large amount of scatter is therefore expected. Bell et al. (2001) present details of the expected sampling errors from a TRMM-like orbit. Results indicate that random sampling errors may be approximated by $\sigma / R(\%)=$ $0.26 R^{-0.27}\left(R: \mathrm{mm}^{-1}\right)$, which leads to a sampling error of approximately $30 \%$ for accumulations of $500 \mathrm{~mm}$ 
(a) TMI vs. Atolls

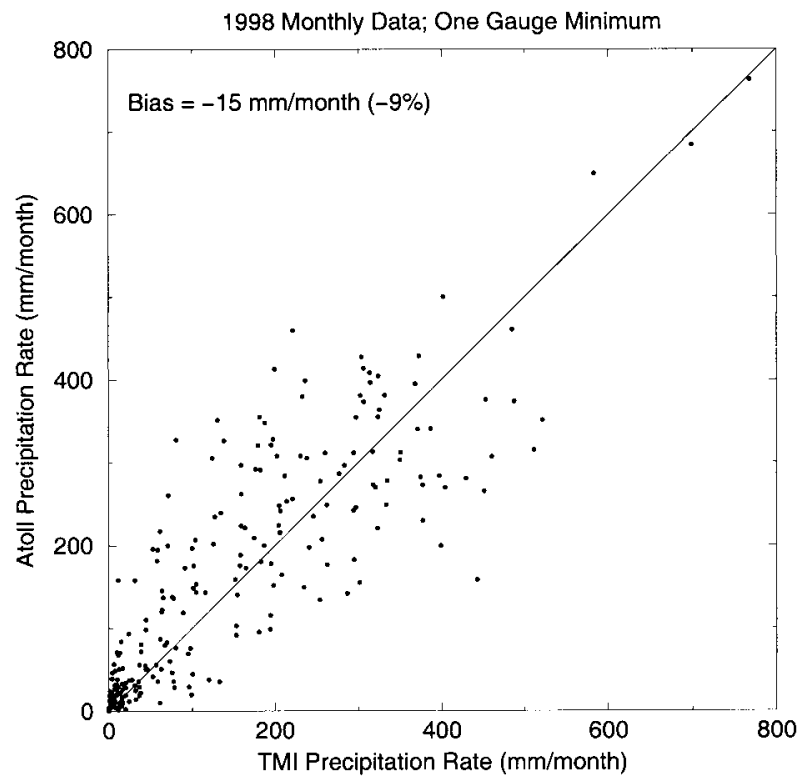

(b) TMI vs. Atolls

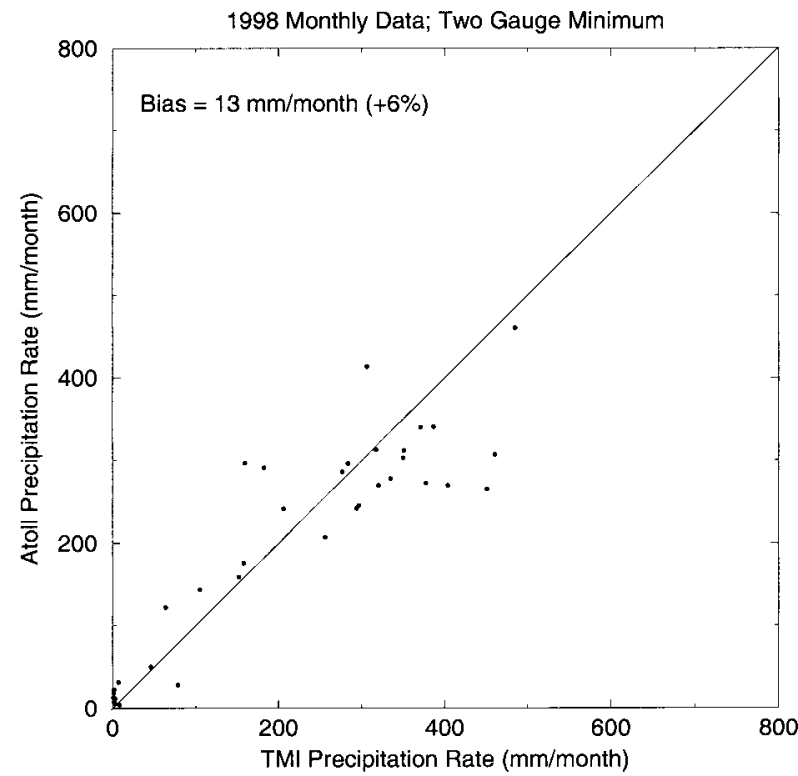

FIG. 4. Comparison of monthly $\left(2.5^{\circ}\right)$ GPROF version-5 oceanic rain estimates with rain gauge data from low-lying atoll sites: (a) all grid boxes having at least one atoll gauge; (b) grid boxes having at least two rain gauges.

month $^{-1}$. Sparse rain gauges in a number of grid boxes contribute to an additional source of uncertainty.

Despite significant random errors, biases should be small when 6700 gauges are considered. Overall, the GPROF version-5 algorithm is seen to have a positive bias $(+17 \%)$ and a correlation of 0.80 with the analyzed gauge product. While it appears that significant numbers

\section{TMl vs. GPCC Gauges}

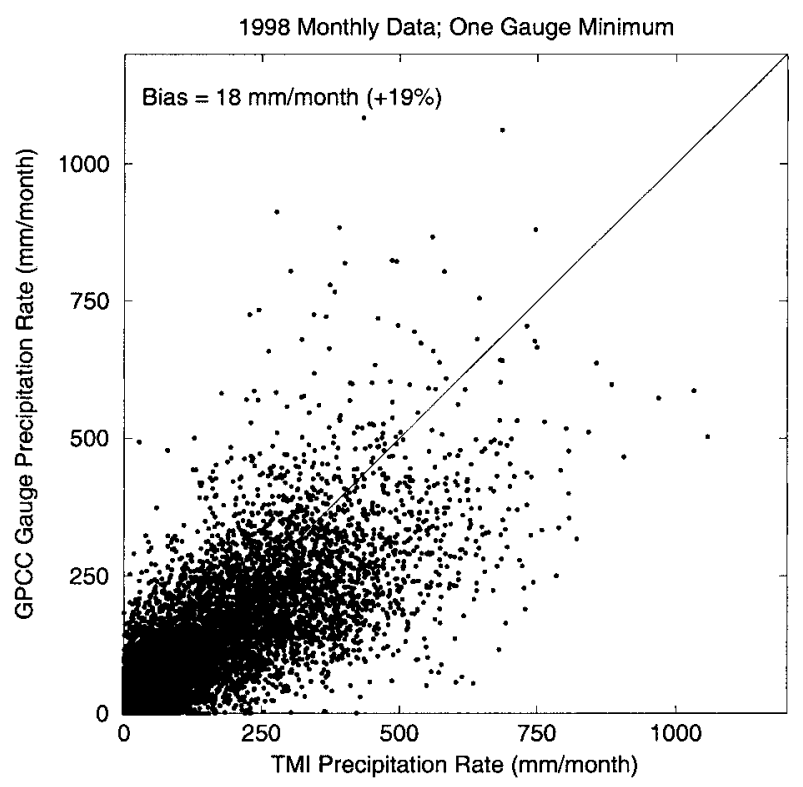

FIG. 5. Comparison of monthly $\left(2.5^{\circ}\right)$ GPROF version-5 land rain estimates with rain gauge data from the GPCC project. of gauges are available over land, it must be recognized that most of these gauges are concentrated over industrialized nations and do not necessarily represent a true global mean.

\section{b. Kwajalein Atoll radar data}

GPROF ocean rain estimates are compared with rainfall derived from the ground-based radar operated at the Kwajalein Atoll. This S-band polarized (WSR-93D) radar has been operated at Kwajalein Atoll, Republic of the Marshall Islands, since the launch of TRMM as part of the TRMM validation effort. The radar is located at $8.72^{\circ} \mathrm{N}, 167.73^{\circ} \mathrm{W}$. It has been operated continuously except for a 3-month period (mechanical difficulties) and maintenance periods. (Details on the radar and its operation can be found at http://trmm.gsfc.nasa.gov.) Two groups, using separate techniques, make rainfall estimates from this radar. The first is the TRMM official algorithm.

The official algorithm recognized that radar calibration would always be a large source of error in making quantitative rainfall estimates. To overcome this problem, a bulk-adjustment approach was adopted to force the radar data into agreement with collocated rain gauges. Rain maps are generated by interpolating the raw polar radar data onto Cartesian coordinates with a horizontal resolution of $2 \mathrm{~km}$. Rainfall is classified into convective and stratiform rain according to the horizontal radar reflectivity structure developed by Steiner et al. (1995). For each type of rainfall, the monthly accumulation of the radar pixels [derived using a default 


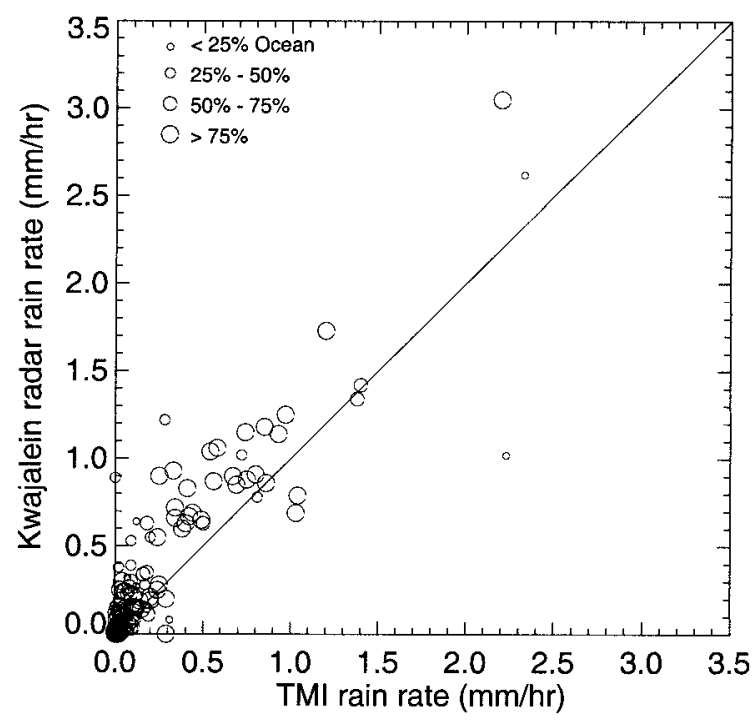

FIG. 6. Comparison of instantaneous GPROF version-5 oceanic rainfall estimated with operational TRMM estimates made from the Kwajalein radar. The size of the open circles indicates the percentage of the radar covered during a given satellite overpass.

relationship of $Z=300 R^{1.4}$, Fulton et al. (1998)] directly above each gauge location is compared with the 7-min rain gauge accumulation for the corresponding gauge. A final, gauge-adjusted relationship between radar reflectivity $(Z)$ and rainfall rate $(R)$ is derived for each site and for each month using

$$
Z_{i}=300\left(R_{i} / G_{i}\right)^{1.4} R_{i}^{1.4},
$$

where $R$ is the total rainfall accumulated by the radar over the locations of the gauges that passed a quality control procedure, $G$ is the rainfall accumulated from tipping-bucket rain gauge data, and the subscript $i$ refers to either convective or stratiform rainfall. Rain rates from gauge and radar data were both accumulated over 7-min intervals, but tests showed that results do not change much for different time intervals. This bulk adjustment is applied to one month of data from each site, with separate $Z-R$ relationships derived for convective and stratiform rainfall. If the total rainfall accumulated over all of the gauges for a month is less than $250 \mathrm{~mm}$, then the bulk adjustment procedure is applied to consecutive months of data.

Comparisons between the GPROF product and the rainfall products generated by the above algorithm for all overpasses in 1998 are presented in Fig. 6. The absence of points on either axis points out that over areas of $1^{\circ}$ or so, discrimination between rain and no rain is nearly perfect over oceans. Of the 283 overpasses having data in 1998, 144 were classified as having no rain in both the satellite and radar; 126 were classified as having at least $0.01 \mathrm{~mm} \mathrm{~h}^{-1}$ in both satellite and radar, and only 13 cases were recorded in which either the satellite or radar recorded greater than $0.01 \mathrm{~mm} \mathrm{~h}^{-1}$, while the other one recorded no rain. This represents

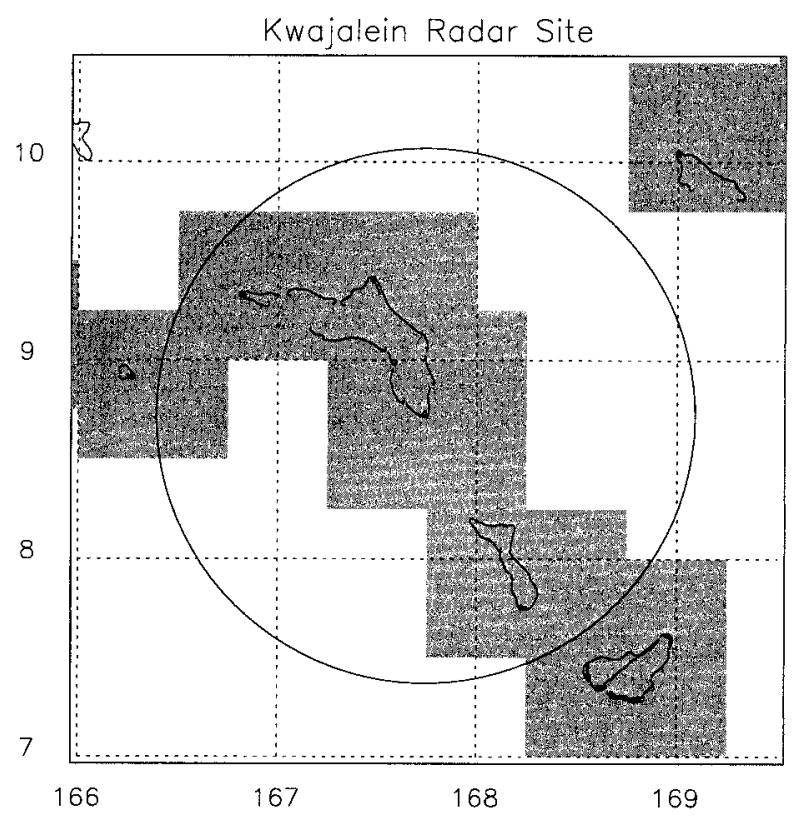

FIG. 7. Surface classification used by GPROF in the Kwajalein vicinity. Shaded areas correspond to coastal grid boxes, while white areas are deemed oceanic.

less than $4.5 \%$ misclassification, and it is always with light rain. At a resolution of $25 \mathrm{~km}$ commensurate with the TMI low-resolution channels, approximately 22300 coincident grid boxes were observed. Of these, 20240 were classified as nonraining by both the TMI and the Kwajalein radar, while 1606 grid boxes were correctly classified as raining by both instruments, and 474 were misclassified as raining $\left(R>0.5 \mathrm{~mm} \mathrm{~h}^{-1}\right)$ by either the TMI or the radar but not the other. The number of misclassified pixels reduces to 234 if a threshold of $1 \mathrm{~mm}$ $\mathrm{h}^{-1}$ is used to define rainfall.

The results shown in Fig. 6 correspond to accumulations over the radar coverage that is deemed to be "ocean" by the retrieval algorithm. While Kwajalein can be thought of as a pure oceanic environment, the GPROF surface-type mask has sufficient spatial resolution $\left(0.25^{\circ}\right)$ that it recognizes the atoll as being a mixture of land and ocean. As such, it classifies some of the pixels as coastline. Figure 7 shows the classification of the area surrounding Kwajalein. The dark areas are considered to be "coast." In the operational version of the algorithm, coastline is treated as "land" and these pixels are therefore excluded from the comparison. The comparisons are for instantaneous rainfall averaged over the entire area of overlap between the satellite and the ground-based radar. The different size circles are used to indicate the percent coverage of the domain, with $100 \%$ signifying the entire ocean area. Given the mixture of ocean and coast areas, as well as an often incomplete coverage of the entire radar FOV, the mean area of overlap is approximately $1^{\circ} \times 1^{\circ}$ but varies from overpass to overpass. The correlation between the two 
1998 Zonal Profile Averages
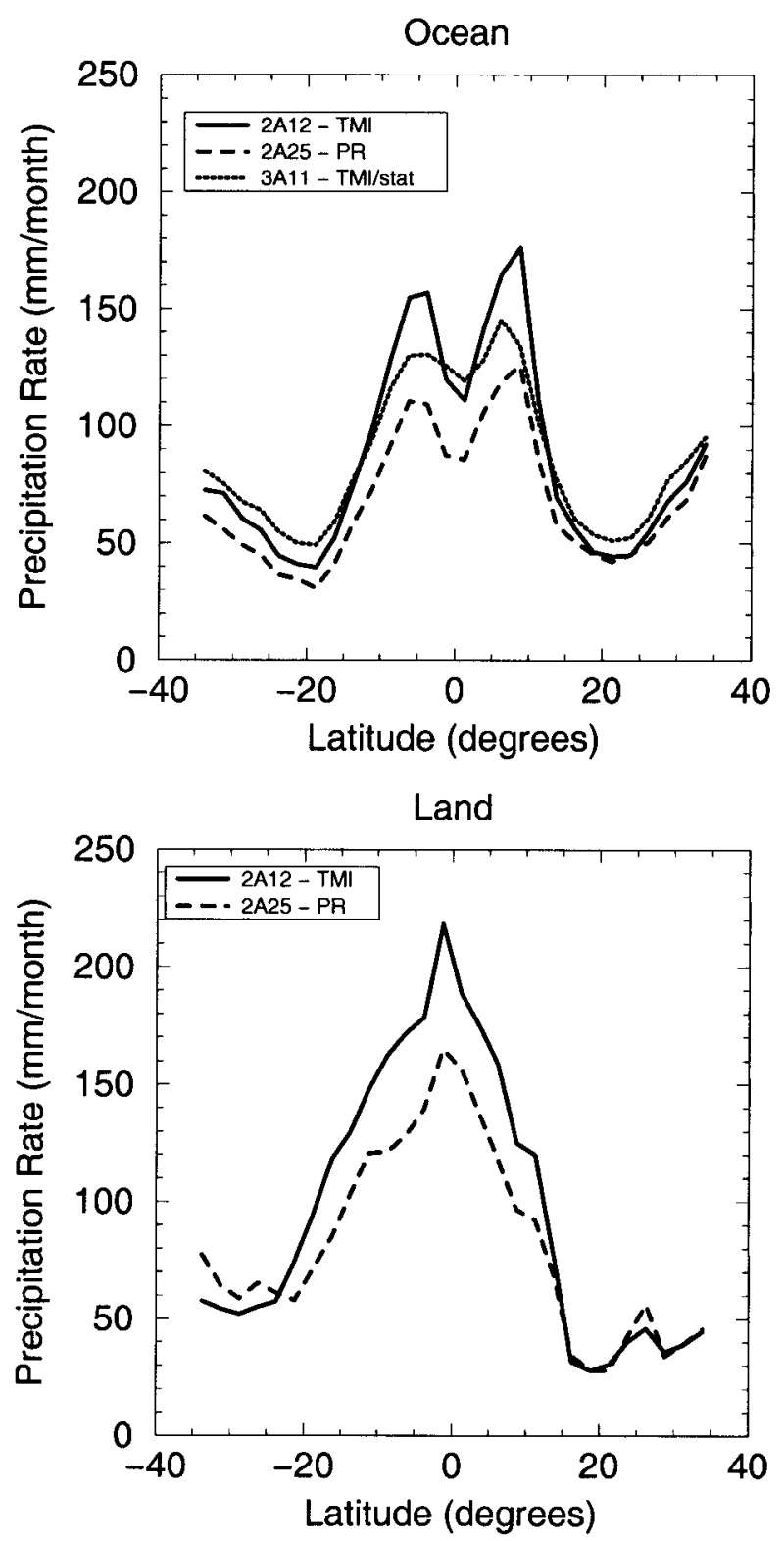

FIG. 8. Mean zonal profiles of precipitation from selected TRMM products over (a) ocean and (b) land. Numbers indicate the product referenced to the TRMM Data and Information System, where "2A12" is the current GPROF-V5 algorithm, "2A25" refers to the PR rainfall products, and " $3 \mathrm{~A} 11$ " refers to the microwave emission algorithm described in the introduction. estimates is quite high, with $r=0.95$ for the entire year of 1998. Biases, however, are significant, with the GPROF estimate being 32\% lower than the groundbased radar. This result would imply that GPROF, despite being positively biased relative to the other TRMM products, is still too low when compared with the Kwajalein radar data.

An independent estimate of rainfall over Kwajalein is made by the University of Washington TRMM group (http://www.atmos.washington.edu/gcg/MG/KWAJ). In their estimate, the overall calibration of the Kwajalein radar is first adjusted to match the TRMM precipitation radar, which is known to be quite stable and thought to be calibrated to $\pm 1 \mathrm{dBZ}$ (Kummerow et al. 2000). Unlike the bulk adjustment method, this technique uses climatological drop size distributions measured by Mueller and Sims (1967) and recently confirmed during the TRMM field experiment at Kwajalein. While results were not yet available for all of 1998 from this technique, monthly accumulations during the three most rainy months (accounting for over $80 \%$ of the total observed rain in 1998) tend to be significantly lower than the "official" products described above. Rainfall totals for the three months of overlap show this technique yields only $57 \%$ of the rainfall produced by the bulk adjustment technique. When compared with this technique, GPROF would therefore overestimate rainfall by approximately $17 \%$ (instead of underestimating by $32 \%$ ). In short, even "calibrated" radar rainfall estimates are still uncertain to at least $\pm 25 \%$.

\section{c. Other TRMM estimates}

\section{1) SURFACE RAIN-RATE COMPARISONS}

Figure 8 compares zonal mean rainfall estimates from the GPROF algorithm with other TRMM products. The top panel of Fig. 8 corresponds to oceanic estimates where GPROF is compared with the TMI emission algorithm described in the introductory section and the TRMM precipitation radar (PR) algorithms. The PR algorithm is described in detail by Iguchi et al. (2000). Of greatest importance to this paper may be the fact that, for light and moderate rainfall rates $\left(<10 \mathrm{~mm} \mathrm{~h}^{-1}\right)$, the PR algorithm must use an a priori drop size distribution, while for heavy rainfall the PR must correct for attenuation of the radar beam. Both factors can introduce errors into the PR products. Table 1 presents a short synopsis of the main uncertainties of the three algo-

TABLE 1. Major sources of uncertainty in three TRMM algorithms.

\begin{tabular}{|c|c|c|c|}
\hline Algorithm & Freezing-level height & Rain inhomogeneity & DSD \\
\hline TMI-Emission (3A11) & $\begin{array}{l}\text { Error in freezing level linearly } \\
\text { related to error in surface rain }\end{array}$ & Constant factor & $\begin{array}{l}\text { Not a significant source of } \\
\quad \text { error }\end{array}$ \\
\hline GPROF-V5 (2A12) & Same procedure as $3 \mathrm{~A} 11$ & $\begin{array}{l}\text { Factor varies with } \mathrm{C} / \mathrm{S} \text { ra- } \\
\text { tio }\end{array}$ & $\begin{array}{l}\text { Not a significant source of } \\
\text { error }\end{array}$ \\
\hline Precipitation radar (2A25) & Not a significant source of error & Small effect & $\begin{array}{l}\text { A priori assumption sensi- } \\
\text { tive to errors }\end{array}$ \\
\hline
\end{tabular}


rithms compared in Fig. 8. The double peak in the Tropics occurs from the preferred location of the intertropical convergence zone (ITCZ) during the course of one year at these two locations. Comparisons with the emission algorithm at the $5^{\circ}$ monthly gridbox level reveals a very small bias ( $+6 \%$ for GPROF) and a correlation of 0.97 . The zonal means are generally in good agreement outside the Tropics, but the emission algorithm displays a markedly smaller amplitude in the ITCZ. The cause for the emission algorithm's smaller dynamic range across the ITCZ is speculative at this time but is consistent with the fixed beamfilling correction applied by the emission algorithm as opposed to the dynamic assignment made by the convective-stratiform partitioning. Convective fractions are higher in the ITCZ as determined by both the GPROF algorithm and the PR algorithms and would therefore lead to larger dynamic range than if the rain type (and hence horizontal inhomogeneity) were held constant. This argument is supported by the precipitation radar, which is less sensitive to the beamfilling errors. It shows lower overall accumulations but similar trends in the zonal means. The bias, with respect to the PR, is $+23 \%$ over oceans, and the correlation with GPROF on a monthly $5^{\circ}$ grid box is 0.94 . The reason for the $23 \%$ bias remains an area of active research. The somewhat smaller correlation (despite the greater similarity in the shapes of the zonal means) is likely due, at least in part, to the different sampling of the two instruments.

Over land (Fig. 8, bottom panel), comparisons of the GPROF version-5 rain estimates also appear higher than the PR. The bias in this case is $+20 \%$ and the correlation for monthly $5^{\circ}$ grids is 0.90 . This bias is consistent with the GPCC gauges examined in the previous section. The biggest differences in magnitude, however, are present in the ITCZ where there are very few gauges. The GPCC gauges are concentrated in the $20^{\circ}-30^{\circ}$ latitude belt where both sensors agree quite well. As such, the two results are not yet fully consistent.

The top panel of Fig. 9 presents histograms of rainfall rates at the individual pixel level for GPROF version5 results in comparison with the precipitation radar. While there are differences at the very light rainfall rates where both sensors lose sensitivity, the overall shape of the histograms is seen to agree quite well except for secondary peaks in the GPROF products. These peaks are the result of incomplete databases that tend to cluster results around some preferred values. More profiles in future releases will solve this problem. Histograms shown in the bottom panel of Fig. 9 correspond to $0.5^{\circ}$ average rainfall rates. These histograms are nearly indistinguishable.

\section{2) Vertical Structure COMPARISONS}

The vertical structure from the TMI and PR algorithms is compared in Fig. 10. Comparisons are made from the surface to $8 \mathrm{~km}$ with an interval of $1 \mathrm{~km}$. Direct
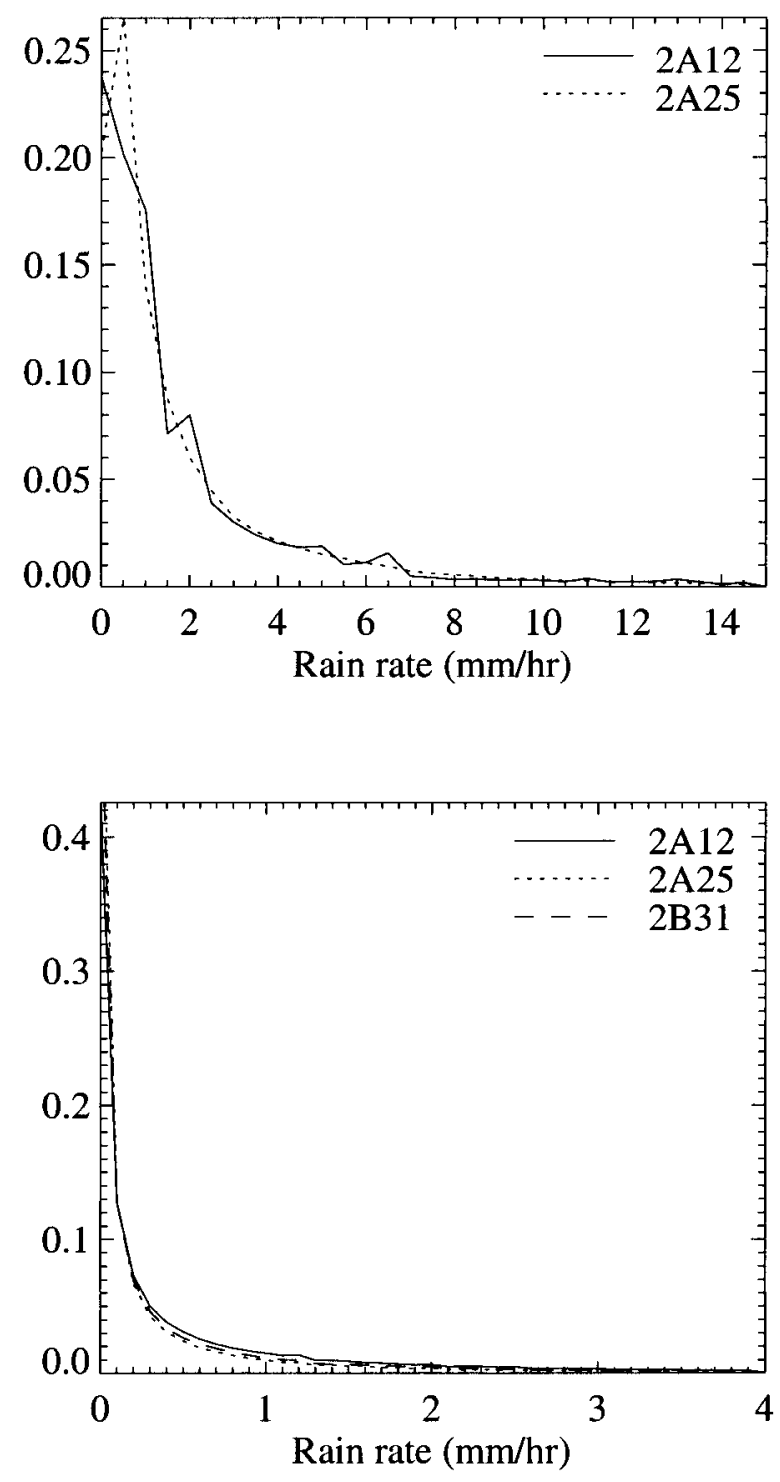

FIG. 9. Histograms of rainfall rates derived from GPROF (2A12) vs PR (2A25) for (top) individual footprints and (bottom) rainfall averaged over $0.5^{\circ}$ grid boxes.

comparisons, however, cannot be made because the TMI generates liquid-ice water concentrations above the surface while the PR derives an equivalent rainfall rate. An equivalent rainfall rate is obtained for the TMI products by applying the technique described by Yang and Smith $(1999,2000)$. This rain profile is further scaled to the original TMI estimate in order not to introduce any additional biases from the conversion algorithm. TMI and PR rain profiles are first grouped into monthly means at $5^{\circ} \times 5^{\circ}$. Their monthly mean rainfall structures are then compared over ocean and land separately.

Figure 10 presents comparison results of rain vertical structure for February 1998, which has been used as a benchmark month for TRMM product intercomparisons. The ratio of the average rainfall rates is shown in the 

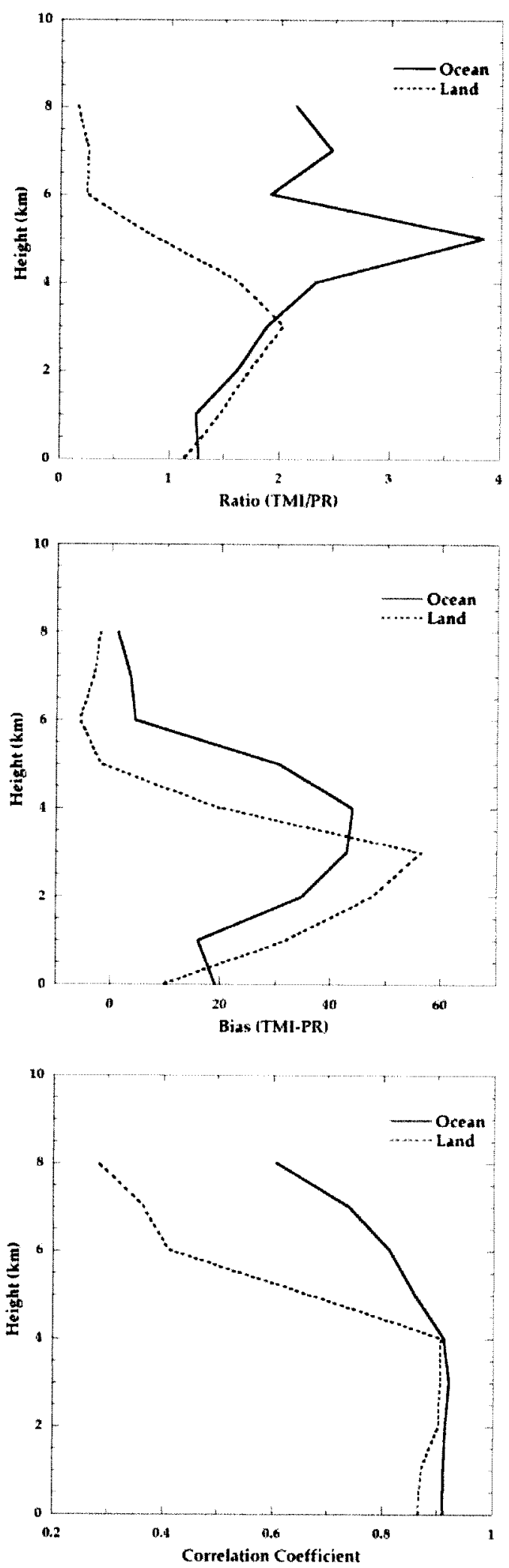

FIG. 10. Comparison of GPROF and PR vertical profiles of hydrometeor profiles converted to an equivalent rainfall rate: (top) the bias in equivalent rainfall rates, (middle) the bias between the two estimates, and (bottom) the correlation. upper panel. TMI oceanic rainfall is about $20 \%$ greater than PR rainfall near surface (consistent with the previous results), but the TMI rainfall rate continues to increase relative to PR with increasing height above the surface. Differences in the oceanic ratios become extreme at the 6-km level, but an examination of the bias reveals that the bias has gone to nearly zero at this altitude. This is due to the loss of meaningful signal by the PR at this height. The explanation for the increasing discrepancy with height lies in the inability of the passive microwave sensor to properly observe the vertical extent of shallow clouds. Because the entire a priori database consists of cloud profiles that extend above the freezing level, the resulting profiles therefore also extend to at least the freezing level. The precipitation radar, on the other hand, observes these shallow systems but will underestimate the small liquid water contents aloft when these fall below the sensitivity of the sensor. These two conditions add to produce the apparent large discrepancy shown in Fig. 10 at top. While the mean ratio of TMI-PR reaches almost a factor of 2, the bias over oceans remains a comparatively small $40 \%$ as indicated in Fig. 10 at middle. This indicates that the large discrepancies occur primarily at the light rainfall rates (which dominate the average ratio) but contribute less to the overall rainfall accumulations than do the heavy rainfall cases that dominate the overall bias (Fig. 10, middle). The correlation coefficient remains nearly constant below the freezing level. This is an indication that some systematic differences are being observed. The drop in correlation above the freezing level is to be expected because ice hydrometeors are more difficult to interpret-particularly any conversions from ice scattering signatures to an effective rainfall rate. Results are nearly identical for land precipitation below the freezing level. This further lends credence to the hypothesis that the cloud model profiles, which in the case of land precipitation simply relate the amount of ice scattering to the surface rainfall, do not properly match the vertical hydrometeor structure seen by the PR. Above the freezing level, the TMI land profiles become much smaller than the PR profiles. This is likely due to the different assumptions about ice densities (and hence scattering efficiency) between the two algorithms.

Monthly rainfall bias over ocean and land is shown in the middle panel. It can be seen that TMI rain overestimates as much as $42(58) \mathrm{mm}$ around $3-4 \mathrm{~km}$, while only about 19 (10) $\mathrm{mm}$ near the surface over ocean (land).

Their correlation coefficient below $4 \mathrm{~km}$ is about 0.91 for ocean and 0.90 for land. Over ocean, the correlation coefficient is always greater than 0.6 above $4 \mathrm{~km}$. However, it decreases dramatically above $4 \mathrm{~km}$ over land. Since the two algorithms assume somewhat different ice characteristics, this implies that oceanic precipitation is less variable when it comes to ice characteristics than continental convection. A completed comparison analysis of TRMM version-4 rain products can be found in 


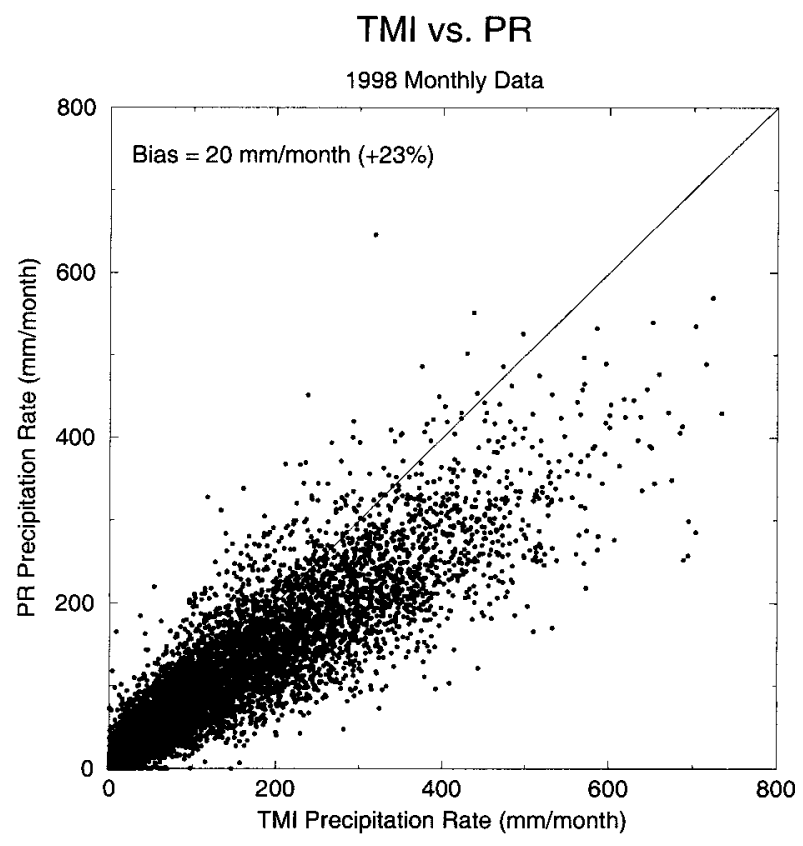

FIG. 11. Scatter plot for $5^{\circ} \times 5^{\circ}$ monthly rainfall accumulations from GPROF and PR. Correlation is 0.91 over oceans and 0.90 over land. Some of the noise is due to the larger sampling volume observed by the TMI.

a technical report by Smith and Yang (1998). Comparison of that report with the current progress report shows improvements in the correlation coefficients from 0.6 to 0.9 for TRMM version- 5 products. The scatterplot of $5^{\circ}$ monthly mean surface rainfall for TMI and PR is shown in Fig. 11. Much of the scatter is due to the differences in the sampling of the two sensors.

\section{d. Comparisons with the NESDIS operational products}

As mentioned at the outset of this paper, the NESDIS operational algorithm was adopted over land. This was done in part because neither algorithm was demonstrably superior to the other. In addition, a lot of effort was being put into improving rainfall estimates in idealized situations and not enough attention was being placed on difficult operational issues such as screening of snow covered surfaces or the careful validation over different climatic regimes. The first comparison is therefore between the TMI version-5 algorithm and the NESDIS SSM/I rainfall products. These should, by design, be very similar if not identical. Figure 12 shows the comparisons of the zonal means and indeed verifies that the TMI version 5 and the SSM/I SI are nearly identical. Both are also very similar to the GPCP product [although somewhat higher $(\sim 12 \%)$ ], while version 4 of the TRMM algorithm is seen to have had some problems that were primarily due to poor screening routines.

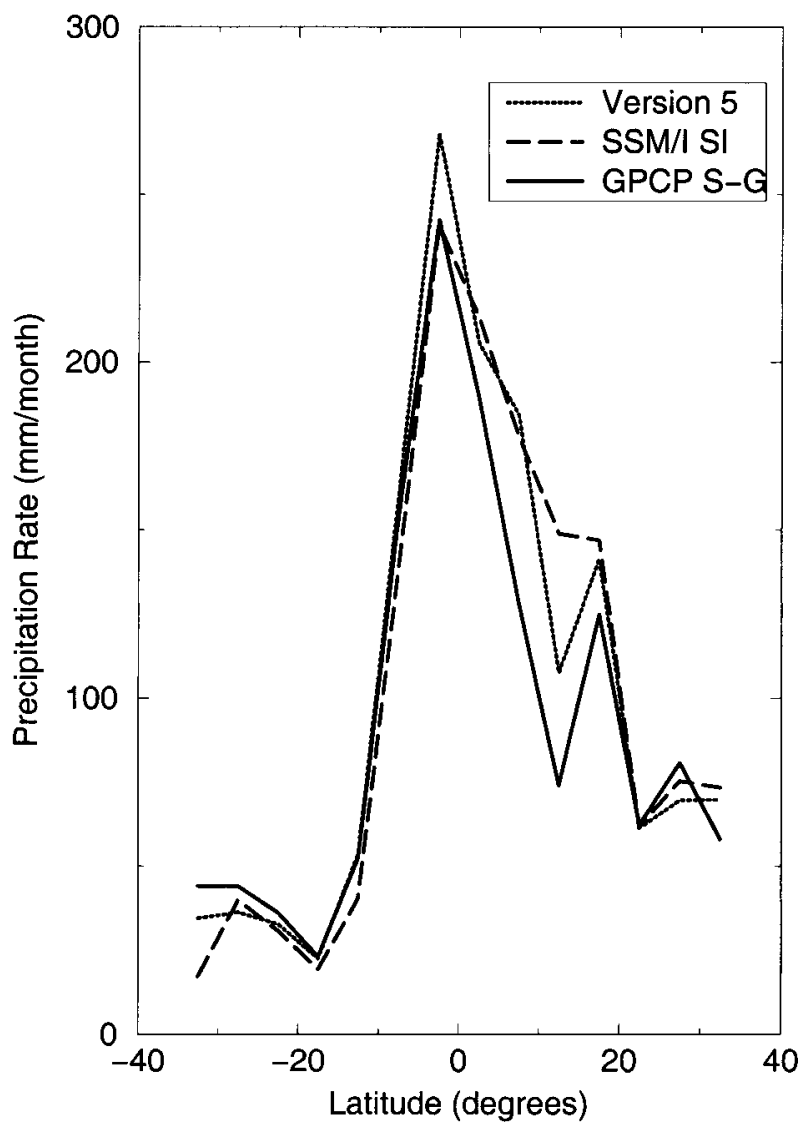

FIG. 12. Comparison of mean monthly rainfall (Apr-May 1999) over land for $5^{\circ}$ latitude bands. The two GPROF TMI versions are compared with the GPCP satellite-gauge product and the NESDIS $\mathrm{SSM} / \mathrm{I}$ product.

\section{Known issues and concluding remarks}

The GPROF algorithm is continuously evolving as new sensors [e.g., advanced microwave scanning radiometer (AMSR) and AMSR-E] become available, new cloud model databases are generated, or our understanding of clouds and precipitation processes improves. Based upon available ground-based data, GPROF appears to be performing within the uncertainties of these measurements. There are, nonetheless, a number of open issues that must still be addressed in order to put the algorithm on a theoretically firmer ground and to pave the way for physically derived uncertainty estimates. These are discussed next.

\section{a. Improvements in database and radiative transfer modeling}

As a result of the TRMM field campaign, cloud-resolving models are undergoing significant changes in their treatment of ice microphysics. This, coupled with continuous improvements in the formulation of these cloud models, will result in even more sophisticated models that are available for the a priori database. New 
model simulations will be incorporated into GPROF as they become available. Uniformly computed latent heating profiles are given as a requirement for the next version of the GPROF algorithm.

In addition to the improved models, the next version of GPROF will also replace the simplified one-dimensional radiative transfer computation with a fully threedimensional Monte Carlo code as developed by Roberti et al. (1994), as well as explicit antenna gain function to convolve the model brightness temperature field to observed resolution. These changes are not believed to have a large impact upon the results but do represent a more exact treatment of the problem. The new models and radiative transfer codes are explicitly accounted for melting particles. Including the melting layer is expected to reduce the stratiform rainfall by $5 \%$ to $10 \%$.

\section{b. Physical inconsistency between PR and TMI}

The GPROF and TRMM radar differences need to be resolved through a physically consistent model of precipitation physics, backed by in-cloud observations. Early work by Viltard et al. (2000) has shown that the current PR-retrieved rainfall amounts, when combined with a cloud model to fill in the unknown cloud water amounts, do not yield the observed radiometer brightness temperatures. A number of factors or combination of these can be responsible for the current lack of agreement. Smaller drops in the PR-assumed rain profile would yield consistency, as would a slight reclassification of PR convective and stratiform rainfall categories [(because these have intrinsically different drop size distributions (DSD)]. A third issue could be the lack of a melting level in the radiometer algorithm. Each of these three issues has the correct effect of bringing the radar and radiometer closer to a physically consistent set of observations. The TRMM field experiments measured all three of the phenomena. While the experiments have been completed, the data analysis has just begun. It is therefore too early to draw conclusions.

\section{c. High-latitude precipitation}

It should be noted that all the model simulations currently used in the GPROF database are tropical in nature. This is a reasonably good assumption for TRMM but is not adequate outside the Tropics. To retrieve rainfall outside the Tropics, the current database is adjusted by removing the lowest levels of the cloud model simulations until the appropriate surface temperature is reached. This is a poor representation of the actual cloud systems in extratropical zones. Work is under way to incorporate realistic simulations corresponding to a variety of extratropical environments.

Because integrated liquid water is directly related to the brightness temperatures, one can assume that the rainfall rates in the Tropics should appear reasonable. The same cannot be said for latent heating. Latent heat- ing derived from GPROF depends strongly upon the realism of the cloud model simulations and is therefore not retrieved in extratropical zones at this time. Details of the vertical hydrometeor profiles are retrieved but should be viewed with suspicion.

\section{d. Improvements over land}

Based upon a consistent bias from the GPCC rain gauge as well as the TRMM PR comparisons, GPROF version-5 data will be carefully compared with additional TRMM sources as well as other ground validation data. If a consistent bias can be identified with additional data sources, the GPROF land algorithm (as well as the NESDIS SSM/I) algorithms will be modified to match the existing validation data. This is justifiable because land retrievals are by their very nature empirical. The only useful radiometric signature comes from precipitation-size ice scattering, which is not physically related to the rainfall itself. Oceans, in contrast, offer a strong physical basis for both the radar and radiometer algorithms, and no tuning is planned unless there is physically direct evidence to indicate that a change in the current assumptions is warranted.

Despite a number of areas in which improvements are being sought, GPROF appears to be performing at least at the level at which ground-based validation is possible. Over the atoll rain gauge network, GPROF is essentially unbiased $(-9 \%$ or $+6 \%$ depending on the atoll selection criterion). Over the Kwajalein radar, correlations were quite high, but the magnitude is different. The magnitude was brought into question because of inherent uncertainties in ground-based radar rainfall estimates. The consistent bias between TMI and PR, however, offers hope that the two estimates can be brought within a few percent once the underlying causes of the differences are understood. This problem will therefore receive the greatest attention, using the field experiment data to test all the assumptions that could lead to the current differences. Over land, a more consistent picture is beginning to emerge. Some additional comparisons will be undertaken to verify the GPROF positive bias.

Acknowledgments. The authors thank NASA and Ramesh Kakar in particular for funding the effort to continuously update the rainfall retrieval algorithms. The authors also thank Toshio Iguchi of the Communications Research Laboratory of Japan for many helpful discussions about the potential sources of discrepancies among our algorithms.

\section{REFERENCES}

Adler, R. F., G. J. Huffman, and P. R. Keehn, 1994: Global tropical rain estimates from microwave-adjusted geosynchronous IR data. Remote Sens. Rev., 11, 125-152.

,-- D. D. Bolvin, S. Curtis, and E. J. Nelkin, 2000: Tropical rainfall distributions determined using TRMM combined with 
other satellite and rain gauge information. J. Appl. Meteor., 39, 2007-2023.

Barber, P. W., and S. C. Hill, 1990: Light Scattering by Particles: Computational Methods. World Scientific, $276 \mathrm{pp}$.

Bauer, P., J. P. V. Poiares Baptista, and M. Iulis, 1999: On the effect of the melting layer on microwave emission of clouds over the ocean. J. Atmos. Sci., 56, 852-867.

Bell, T. L., P. K. Kundu, and C. D. Kummerow, 2001: Sampling errors of SSM/I and TRMM rainfall averages: Comparison with error estimates from surface data and a simple model. J. Appl. Meteor., 40, 938-954.

Bellows, C. T., 1999: Consistency testing of models used to infer rainfall from TRMM passive microwave observations. M.S. thesis, Department of Atmospheric Science, Texas A\&M University, College Station, TX, $53 \mathrm{pp}$.

Brock, F. V., K. C. Crawford, R. L. Elliott, G. W. Cuperus, S. J. Stadler, H. L. Johnson, and M. D. Eilts, 1995: The Oklahoma Mesonet: A technical overview. J. Atmos. Oceanic Technol., 12, $5-19$.

Chang, A. T. C., L. S. Chiu, and T. T. Wilheit, 1993: Oceanic monthly rainfall derived from SSM/I. Eos, Trans. Amer. Geophys. Union, 74, 505-513.

,-- C. Kummerow, and J. Meng, 1999: First results of the TRMM microwave imager (TMI) monthly oceanic rain rate: Comparison with SSM/I. Geophys. Res. Lett., 26, 2379-2382.

Churchill, D. D., and R. A. Houze Jr., 1984: Development and structure of winter monsoon cloud clusters on 10 December 1978. J. Atmos. Sci., 41, 933-960.

Daley, R., 1991: Atmospheric Data Analysis. Cambridge University Press, $457 \mathrm{pp}$.

Draine, B. T., and P. J. Flatau, 1988: Discrete dipole approximation for scattering calculations. Astrophys. J., 333, 848-872.

Farrar, M. R., and E. A. Smith, 1992: Spatial resolution enhancement for terrestrial features using deconvolved SSM/I microwave brightness temperatures. IEEE Trans. Geosci. Remote Sens., 30, $349-355$.

Ferraro, R. R., 1997: Special Sensor Microwave Imager-derived global rainfall estimates for climatological applications. J. Geophys. Res., 102 (D14), 16 715-16 735.

_ , and G. F. Marks, 1995: The development of SSM/I rain rate retrieval algorithms using ground-based radar measurements. $J$. Atmos. Oceanic Technol., 12, 755-770.

_ E. A. Smith, W. Berg, and G. J. Huffman, 1998: A screening methodology for passive microwave precipitation retrieval algorithms. J. Atmos. Sci., 55, 1583-1600.

Fulton, R. A., J. P. Breidenbach, D.-J. Seo, and D. A. Miller, 1998: The WSR-88D rainfall algorithm. Wea. Forecasting, 13, 377395.

Grody, N. C., 1991: Classification of snow cover and precipitation using the Special Sensor Microwave Imager. J. Geophys. Res., 96, 7423-7435.

Haferman, J. L., 1999: Microwave scattering by precipitation. Light Scattering by Nonspherical Particles: Theory, Measurements, and Applications. M. I. Mishchenko, J. W. Hovenier, and L. D. Travis, Eds., Academic Press, 481-524.

Heymsfield, G. M., and R. Fulton, 1994a: Passive microwave and infrared structure of mesoscale convective systems. Meteor. Atmos. Phys., 54, 123-139.

$\longrightarrow$, and — 1994b: Passive microwave structure of severe tornadic storms on 16 November 1987. Mon. Wea. Rev., 122, $2587-$ 2595.

Hong, Y., C. D. Kummerow, and W. S. Olson, 1999: Separation of convective and stratiform precipitation using microwave brightness temperature. J. Appl. Meteor., 38, 1195-1213.

Huffman, G. J., and Coauthors, 1997: The Global Precipitation Climatology Project (GPCP) combined precipitation dataset. Bull. Amer. Meteor. Soc., 78, 5-20.

Iguchi, T., T. Kozu, R. Meneghini, J. Awaka, and K. Okamoto, 2000: Rain-profiling algorithm for the TRMM precipitation radar. $J$. Appl. Meteor., 39, 2038-2052.
Jackson, J. D., 1962: Classical Electrodynamics. John Wiley and Sons, $848 \mathrm{pp}$.

Kummerow, C., 1993: On the accuracy of the Eddington approximation for radiative transfer in the microwave frequencies. $J$. Geophys. Res., 98, 2757-2765.

— W. W. S. Olson, and L. Giglio, 1996: A simplified scheme for obtaining precipitation and vertical hydrometer profiles from passive microwave sensors. IEEE Trans. Geosci. Remote Sens., 34, 1213-1232.

—_ W. Barnes, T. Kozu, J. Shiue, and J. Simpson, 1998: The Tropical Rainfall Measuring Mission (TRMM) sensor package. $J$. Atmos. Oceanic Technol., 15, 808-816.

_ - and Coauthors, 2000: The status of the Tropical Rainfall Measuring Mission (TRMM) after two years in orbit. J. Appl. Meteorol., 39, 1965-1982.

Liebe, H. J., G. A. Hufford, and M. G. Cotton, 1993: Propagation modeling of moist air and suspended water/ice particles at frequencies below $1000 \mathrm{GHz}$. AGARD Conf. Proc., 542, 3.1-3.10.

Lin, Y.-L., R. D. Farley, and H. D. Orville, 1983: Bulk parameterization of the snow field in a cloud model. J. Climate Appl. Meteor., 22, 1065-1092.

Lorenc, A. C., 1986: Analysis methods for numerical weather prediction. Quart. J. Roy. Meteor. Soc., 112, 1177-1194.

Marshall, J. S., and W. M. Palmer, 1948: The distribution of raindrops with size. J. Meteor., 5, 165-166.

Morrissey, M. L., M. A. Shafer, S. Postawko, and B. Gibson, 1995: Pacific raingauge data. Water Resour. Res., 31, 2111-2113.

Mueller, E. A., and A. L. Sims, 1967: Raindrop distributions at Majuro Atoll, Marshall Islands. Tech. Rep. ECOM-02071-RR1, United States Army Electronics Command, 93 pp.

Olson, W. S., C. D. Kummerow, Y. Hong, and W.-K. Tao, 1999: Atmospheric latent heating distributions in the Tropics derived from satellite passive microwave radiometer measurements. $J$. Appl. Meteor., 38, 633-664.

— - P. Bauer, C. D. Kummerow, Y. Hong, and W.-K. Tao, 2001a: A melting-layer model for passive/active microwave remote sensing applications. Part II: Simulation of TRMM observations. J. Appl. Meteor., 40, 1164-1179.

— polarization method for estimating convective-stratiform precipitation area coverage from passive microwave radiometer data. J. Appl. Meteor., 40, 1577-1591.

Panegrossi, G., and Coauthors, 1998: Use of cloud model microphysics for passive microwave-based precipitation retrieval: Significance of consistency between model and measurement manifolds. J. Atmos. Sci., 55, 1644-1673.

Petty, G. W., 1994: Physical retrievals of over-ocean rain rate from multichannel microwave imager. Part I: Theoretical characteristics of normalized polarization and scattering indices. Meteor. Atmos. Phys., 54, 79-99.

—_, and J. Turk, 1996: Observed multichannel microwave signatures of spatially extensive precipitation in tropical cyclones. Preprints, Eighth Conf. on Satellite Meteorology and Oceanography, Atlanta, GA, Amer. Meteor. Soc., 291-294.

Roberti, L., J. Haferman, and C. Kummerow, 1994: Microwave radiative transfer through horizontally inhomogeneous precipitating clouds. J. Geophys. Res., 99, 16 707-16 718.

Robinson, W., C. Kummerow, and W. S. Olson, 1992: A technique for matching the resolution of microwave measurements from the SSM/I instrument. IEEE Trans. Geosci. and Remote Sens., 30, 419-429.

Rudolf, B., H. Hauschild, W. Rüth, and U. Schneider, 1996: Comparison of raingauge analyses, satellite-based precipitation estimates, and forecast model results. Adv. Space Res., 18, 53-62.

Schols, J., J. Hafermann, J. Weinman, C. Prabhakara, M. Cadeddu, and C. Kummerow, 1997: Polarized microwave radiation model of melting deformed hydrometeors. Preprints, Ninth Conf. on Atmospheric Radiation, Long Beach, CA, Amer. Meteor. Soc., 270-273.

Smith, E. A., and S. Yang, 1998: On validation of TMI, PR and 
combined TRMM facility rain algorithms. TRMM Science Team Meeting Rep. 2, 89 pp.

Spencer, R. W., H. M. Goodman, and R. E. Hood, 1989: Precipitation retrieval over land and ocean with SSM/I: Identification and characteristics of the scattering signal. J. Atmos. Oceanic Technol., 6, 254-273.

Steiner, M., R. A. Houze Jr., and S. E. Yuter, 1995: Climatological characterization of three-dimensional storm structure from operational radar and rain gauge data. J. Appl. Meteor., 34, 19782007.

Tao, W.-K., and J. Simpson, 1993: Goddard Cumulus Ensemble Model. Part I: Model description. Terr. Atmos. Oceanic Sci., 4, 3572.

Tripoli, G. J., 1992a: A nonhydrostatic model designed to simulate scale interaction. Mon. Wea. Rev., 120, 1342-1359.

- 1992b: An explicit three-dimensional nonhydrostatic numerical simulation of a tropical cyclone. Meteor. Atmos. Phys., 49, 229254.
Viltard, N., C. Kummerow, W. S. Olson, and Y. Hong, 2000: Combined use of the radar and radiometer of TRMM to estimate the influence of drop size distribution on rain retrievals. J. Appl. Meteor., 39, 2103-2114.

Wilheit, T. T., 1979: A model for the microwave emissivity of the ocean's surface as a function of wind speed. IEEE Trans. Geosci. Electron., 17, 244-249.

—- A. Chang, and L. Chiu, 1991: Retrieval of monthly rainfall indices from microwave radiometric measurements using probability distribution function. J. Atmos. Oceanic Technol., 8, 118136.

Yang, S., and E. A. Smith, 1999: Moisture budget analysis of TOGA COARE area using SSM/I-retrieved latent heating and largescale $Q_{2}$ estimates. J. Atmos. Oceanic Technol., 16, 633-655.

$\longrightarrow$, and 2000: Vertical structure and transient behavior of convective-stratiform heating in TOGA COARE from combined satellite-sounding analysis. J. Appl. Meteor., 39, 1491-1513. 